\title{
Extracting and Applying SV-SV Shear Modes from Vertical Vibrator Data Across Geothermal Prospects
}

\author{
Final Report \\ Reporting Period Start Date: October 1, 2011 \\ Reporting Period End Date: September 30, 2012
}

Principal Investigator: Bob A. Hardage

Report Issue Date: July 2013

DOE Award Number DE-EE0005512

Submitting Organization:

Bureau of Economic Geology University Station, Box X

Austin, TX 78713-8924 


\section{Disclaimer}

This report was prepared as an account of work sponsored by an agency of the United States Government. Neither the United States Government nor any agency thereof, nor any of their employees, makes any warranty, express or implied, or assumes any legal liability or responsibility for the accuracy, completeness, or usefulness of any information, apparatus, product, or process disclosed, or represents that its use would not infringe privately owned rights. Reference herein to any specific commercial product, process, or service by trade name, trademark, manufacturer, or otherwise does not necessarily constitute or imply its endorsement, recommendation, or favoring by the United States Government or any agency thereof. The views and opinions of authors expressed herein do not necessarily state or reflect those of the United States Government or any agency thereof. 


\begin{abstract}
This 3-year project was terminated at the end of Year 1 because the DOE Geothermal project-evaluation committee decided one Milestone was not met and also concluded that our technology would not be successful. The Review Panel recommended a "no-go" decision be implemented by DOE. The Principal Investigator and his research team disagreed with the conclusions reached by the DOE evaluation committee and wrote a scientifically based rebuttal to the erroneous claims made by the evaluators. We were not told if our arguments were presented to the people who evaluated our work and made the "no-go" decision. Whatever the case regarding the information we supplied in rebuttal, we received an official letter from Laura Merrick, Contracting Officer at the Golden Field Office, dated June 11, 2013 in which we were informed that project funding would cease and instructed us to prepare a final report before September 5 , 2013. In spite of the rebuttal arguments we presented to DOE, this official letter repeated the conclusions of the Review Panel that we had already proven to be incorrect.

This is the final report that we are expected to deliver. The theme of this report will be another rebuttal of the technical deficiencies claimed by the DOE Geothermal Review Panel about the value and accomplishments of the work we did in Phase 1 of the project. The material in this report will present images made from direct-S modes produced by vertical-force sources using the software and research findings we developed in Phase 1 that the DOE Review Panel said would not be successful. We made these images in great haste when we were informed that DOE Geothermal rejected our rebuttal arguments and still regarded our technical work to be substandard. We thought it was more important to respond quickly rather than to take additional time to create better quality images than what we present in this Final Report.
\end{abstract}




\section{Table of Contents}

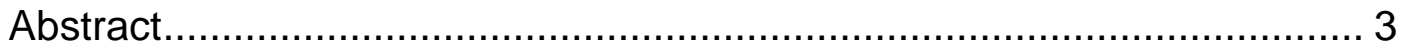

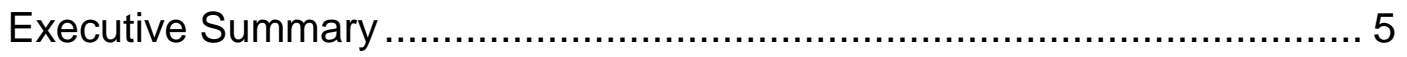

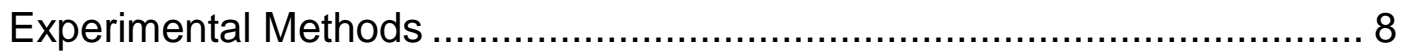

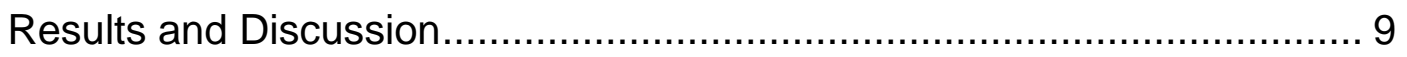

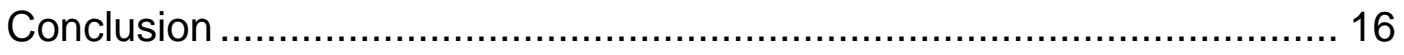

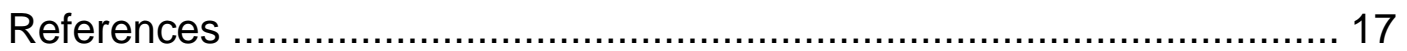

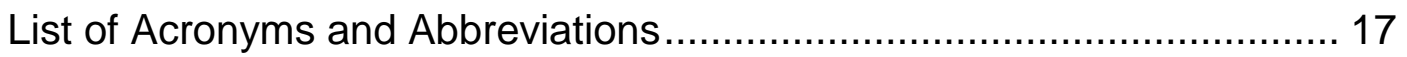

$\begin{array}{ll}\text { Appendix A: DOE No-Go Letter } & 18\end{array}$

Appendix B: Paper 1 in Peer Review 21

Appendix C: Paper 2 in Peer Review 46 


\section{Executive Summary}

The purposes of our study were to demonstrate that: (1) direct-S modes can be extracted from seismic data generated by common vertical-force sources used in P-wave seismic imaging, and (2) these S modes provide valuable fracture and reservoir facies information across geothermal reservoirs. Our project was to be done in two phases. Phase 1 began October 1, 2011 and ended September 30, 2012. Three tasks were to be done in Phase 1:

1. Develop seismic data-processing software to extract direct-S modes.

2. Apply our direct-S imaging technology to seismic test data, and

3. Construct our research database.

Three Milestones were imposed for Phase 1 (Mark Ziegenbein, Project Officer, Email of January 16, 2013), which were:

1. Present a report that demonstrates the technology has the potential for estimating and mapping fracture attributes across geothermal prospects.

2. Demonstrate the remaining budget and cost share are adequate to complete Phase 2.

3. Assess whether site permitting, site access, and environmental documentation can be achieved within the budget and timeframe of Phase 2.

All Milestones established by our Project Officer for Phase 1 were met. However, the DOE Geothermal Project Review Committee concluded that we did not meet Milestone 1 listed at the top of this page because they concluded the evidence we presented in our Continuation Report was not convincing, and that was little likelihood of technical success from our research. We have rebutted their logic in a correspondence sent to our Project Officer (Mark Ziegenbein) in which we presented evidence demonstrating the evaluators had no concept of how seismic data react to fractures and how you must approach the processing of the new Swave modes that we are introducing to the seismic industry. We will rebut the evaluators' conclusions again in this final report using even stronger real-data evidence than what we have presented to date.

We wrote the required Continuation Report in January 2013 to extend the project for the two years of Phase II. We then received a certified letter June 11, 2013 from Laura Merrick, Contracting Officer at the Golden Field Office, which is included as Appendix A of this Final Report. This letter states DOE Geothermal would not continue funding the project beyond Phase I for the following reasons (all of the reasons were repeats of the conclusions reached by the DOE Geothermal Review Panel which we had shown to be incorrect):

1. We had not proven the technology had a reasonable likelihood of success. (We still disagree with DOE on this point. We positively did 
demonstrate a high likelihood of success. We will show the success of what we did in Phase 1 in this Final Report by providing examples of realdata imaging of direct-S modes produced by the software we developed in Phase 1.)

2. We did not meet a critical Milestone. (The Milestone was not identified. The Review Panel stated we did not perform Task 3 [Construct research database] because that task was not mentioned in our Continuation Report. However, the creation of our research database was described in our quarterly report for the period January 1 to March 31, 2012. Thus this claim by the Review Panel that this task was not completed is false. We can resend the quarterly report that discusses our research database if DOE has misplaced it. The only Milestones we discussed in our Continuation Report were the three that were set by our Project Officer (listed on the preceding page). This list did not ask us to include a description of our research database in our Continuation Report. We thus assume the claim that we did not reach a Milestone refers to paragraph 1 immediately above in which the Review Panel concluded our imaging technology would not work. We will once again refute the logic that led the Review Panel to this incorrect conclusion by showing real-data examples of images constructed from the software we developed in Phase 1.)

3. We did not extract fracture attributes. (This reason puzzles us. Milestone 1 provided by our Project Officer was that we were to show our technology had the "potential" to extract fracture attributes. The actual extraction of fracture attributes was clearly set as Tasks $5,7,9$, and 11 in Phase 2, which was not funded. We ask why a No-Go decision was implemented based on a deliverable that was not to be created until Phase 2 work was done.)

The last point we wish to state about the letter from Laura Merrick (Appendix $A$ ) is that it states twice that that our research was evaluated from our Phase 1 report and from our presentation to a Go/No-go Review Panel. We never appeared before a review panel nor were requested to do so. The Principal Investigator did prepare a poster summarizing our Phase 1 work that was displayed at the Year-2013 GTO peer review meeting in Denver. However, the poster session was limited to only Monday evening, and not one DOE person or any DOE project reviewer came by to examine the poster and discuss our work. Thus this poster session could not be the appearance before a review panel that is mentioned in the Merrick letter. We thus ask why is our work judged by a presentation that never occurred?

The key evidence we present in this Final Report that demonstrates the success and high quality of our Phase 1 research will be first-generation images made from direct-S modes extracted from seismic data generated by the 
software we developed in Phase 1. We make the following claim about the images we show in this report.

\section{Claim}

Nowhere in geophysical literature are there any examples of S-S or SV-P images made with data generated by vertical-force sources. The S-S and SV-P images we can now create with our Phase 1 software are historic and represent a seminal change in the methodology that can be used to create S-wave seismic data across any type of geological target, including geothermal fields. These images will be described in upcoming papers published in professional journals.

These images are provided to DOE Geothermal in this Final Report approximately one month after we received the official letter from Laura Merrick stating the technology we were developing had no reasonable likelihood of success. The images were made using the software we developed in Phase 1 that the DOE Review Panel said would not work. What irony.

We particularly encourage DOE Geothermal to share this report and its imaging evidence with the DOE people who reviewed our Phase 1 work. These people could not understand what we were doing and obviously did not understand fundamental principles involved in constructing fracture-sensitive Swave seismic data. We make this request so that these DOE reviewers will be better informed when they assess future research efforts that focus on extraction of fracture attributes from seismic data.

We include two manuscripts as appendices to this report. These manuscripts describe how P-SV converted-S data across Wister geothermal field are more valuable for detecting and characterizing faults, fractures, and reservoir facies than are P-P seismic data. Both manuscripts have been submitted to the journal Interpretation and are now being peer reviewed. The Wister data used in the work described by these two papers is a part of the research database that the DOE Geothermal Review Panel said we failed to create. 


\section{Experimental Methods}

The experimental methods we used in Phase 1 of this project consisted of developing seismic data-processing software that would do two key processes. First, the software would extract direct-S modes from data generated by verticalforce sources. Second, the software would use these extracted S-wave modes to create S-S images across geothermal prospects. The proof-of-concept of the software was demonstrated by working with high-quality seismic data where processing pitfalls could be easily recognized. Only after the software was successfully applied to seismic data with high signal-to-noise ratio were we to apply the software to low signal-to-noise seismic data across the two geothermal prospects we were to study. This final software imaging step across these two geothermal prospects was to be done in Phase 2, which was not funded. 


\section{Results and Discussion}

\section{Direct-S Imaging with Vertical-Force Sources}

We show here examples of S-S images created from multicomponent seismic data generated by vertical-force sources that can be quite useful for evaluating geothermal reservoirs. Two types of vertical-force sources have been utilized to produce these data - vertical vibrators and shot-hole explosives. We first show S-S images made from data generated by a vertical vibrator and recorded with vertical arrays of $3 \mathrm{C}$ geophones. We next show images extracted from surface-based $3 \mathrm{C}$ geophones deployed around this vertical seismic profile (VSP) well as a 3D seismic grid. The energy sources used to generate these surface 3D seismic data were shot-hole explosives. In all data examples, we observe that each type of vertical-force source (vertical vibrator and shot-hole explosive) produces abundant direct-S energy on both radial and transverse geophones. We find only minimal amounts of P-wave energy on transversereceiver data. In contrast, radial-receiver data have significant $P$-wave events intermingled with radial-S events. We find the minimal amount of P-wave noise on transverse-receiver data make it easier to study S-S wave physics and to create S-S images with transverse-S data. The data examples in this paper focus on transverse-S data created by vertical-force sources because interpreters will find it more convenient to process and utilize this direct-S mode.

These direct-S images were made using the software developed in Phase 1 of this project, the same software that DOE Geothermal has described as having no "reasonable likelihood of success" (Laura Merrick letter of June 11, 2013). This letter is included as Appendix A of this report because it will be referenced frequently.

We must emphasize that the direct-S images shown in this report were constructed in haste as soon as we were informed that a No-Go decision would be imposed because the DOE Geothermal Review Panel had concluded our technical approach and our research progress in Phase 1 did not merit continued DOE funding. This hasty image construction makes the quality of the images we display in this report even more impressive because image quality will improve as iterative velocity analysis and iterative static corrections are applied to the data. We have not had time to do these iterative data-processing steps because we wished to respond quickly to DOE's failure to recognize the value of what we did in Phase 1 of the project.

We present three lines of evidence that demonstrate images of geologic targets, including geothermal reservoirs, can be constructed from direct-S modes produced by vertical-force seismic sources. Approach 1 is to construct S-S images from vertical seismic profile (VSP) data; approach 2 is to construct S-S images from surface-recorded data; and approach 3 is to construct SV-P images 
from surface recorded data. These latter images are a spin-off benefit of our research that was not planned when the project started.

\section{Approach 1 - S-S Images from VSP Data}

We particularly want to start with an emphasis on VSP data because: (1) VSP data provide the most fundamental insight into what wave modes are produced by a seismic source and how those modes propagate in the earth, and (2) the DOE Geothermal Review Panel made the following observation about our dependence on VSP data "it seems to the Panel that a walkaround VSP may not be as relevant a test as a line for geothermal applications". We use red-font text to indicate direct quotes.

We show as Figure 1 a data comparison that has never appeared in geophysical literature - this being a comparison of P-P and S-S images constructed from the direct-P mode and the direct-S mode produced simultaneously by a vertical vibrator positioned a far-offset distance from a VSP well. The offset distance from the VSP well to the source station was $4136 \mathrm{ft}$. We also include in this illustration a zero-offset P-P image recorded when the vibrator was moved to be only $252 \mathrm{ft}$ from the VSP well. The S-S image is squeezed in image time to match the P-P image-time scale and to create a depth-equivalence between the P-P and S-S images. The VSP data used to create these images are from the walkaround VSP survey that the DOE Review Panel said "may not be relevant".

Inspection of these images shows that not only is a direct-S mode produced by a vertical vibrator, but that this direct-S mode produces a valuable high-quality S-S image. Regardless of the DOE opinion that it was not appropriate to use VSP data to establish proof-of-concept, and proof-of-concept was all we were to do in Phase 1, we remain steadfast that we had a sound, rigorous approach to demonstrating the basic principles of generating and using direct-S modes produced by vertical vibrator across geothermal prospects by first establishing the principles of S-S imaging using high-quality VSP data.

We consider the images displayed in Figure 1 to be a direct and obvious proof that the DOE Geothermal Review Panel erred in reaching the conclusion they did regarding our technical approach and progress in Phase 1. These data show that, in this instance, the quality of the S-S image created by a vertical vibrator exceeds the quality of the traditional P-P image created by the same vertical vibrator. This image example is new and important information that has never appeared in any geophysical literature. Thus we conclude our research is a seminal change in creating fracture-sensitive information across geothermal reservoirs, which is a position exactly opposite to the written opinion of the DOE Review Panel. This image comparison is now embedded in a technical paper that has been sent for review and publication in a geophysics journal. No one has ever shown any comparison of P-P and S-S images produced simultaneously by 
the same vertical vibrator. Seismic imaging history is being made here, and unfortunately DOE Geothermal has decided to not be a part of it.

(a)

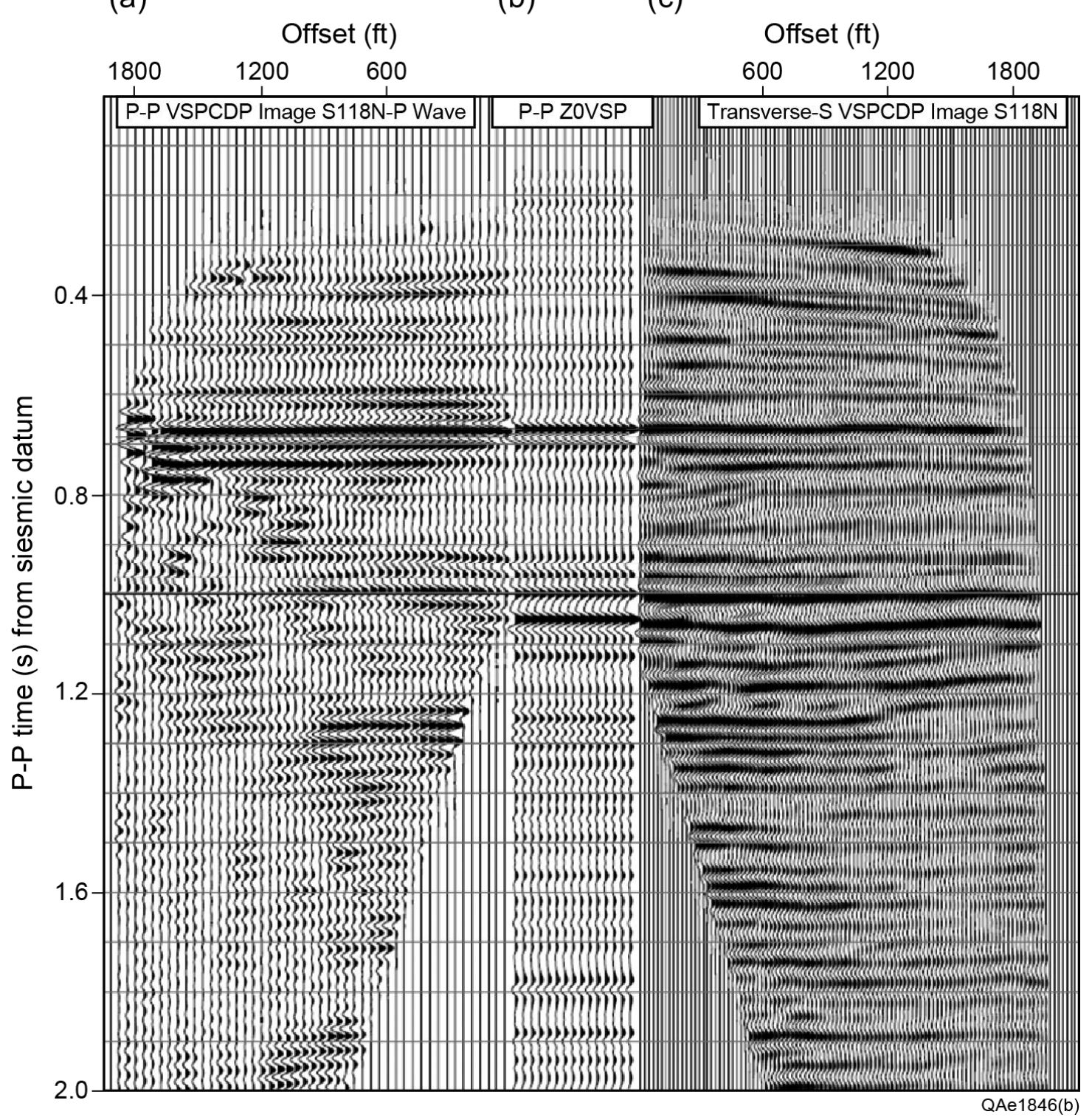

Figure 1. (a) P-P VSP image made from direct-P modes produced at far-offset station A (4136 ft from the receiver well). (b) P-P image made from zero-offset VSP data when a vibrator was positioned only $252 \mathrm{ft}(79 \mathrm{~m})$ from the receiver well. (c) Transverse-S VSP image made from direct-S modes produced simultaneously with the direct-P modes at the same far-offset station $A$. The time scale of the S-S data is adjusted to P-P image time. 


\section{Approach 2 - S-S Images from Surface-Recorded Data}

A modest size 3C3D seismic data volume was recorded around the well where the VSP data presented in Figures 1 were acquired. The energy sources used in this 3D seismic program were shot-holes having a 1-kg explosive positioned at a depth of $6 \mathrm{~m}$. Such shot-hole explosives are another type of vertical-force source. The combination of these VSP data and their associated 3C3D data provide a valuable opportunity to create and compare S-S images produced by two different vertical-force sources - a vertical vibrator and a shothole explosive. It is important for those who interpret seismic data across geothermal reservoirs to know if direct-S modes produced by two different vertical-force sources are equivalent or significantly different.

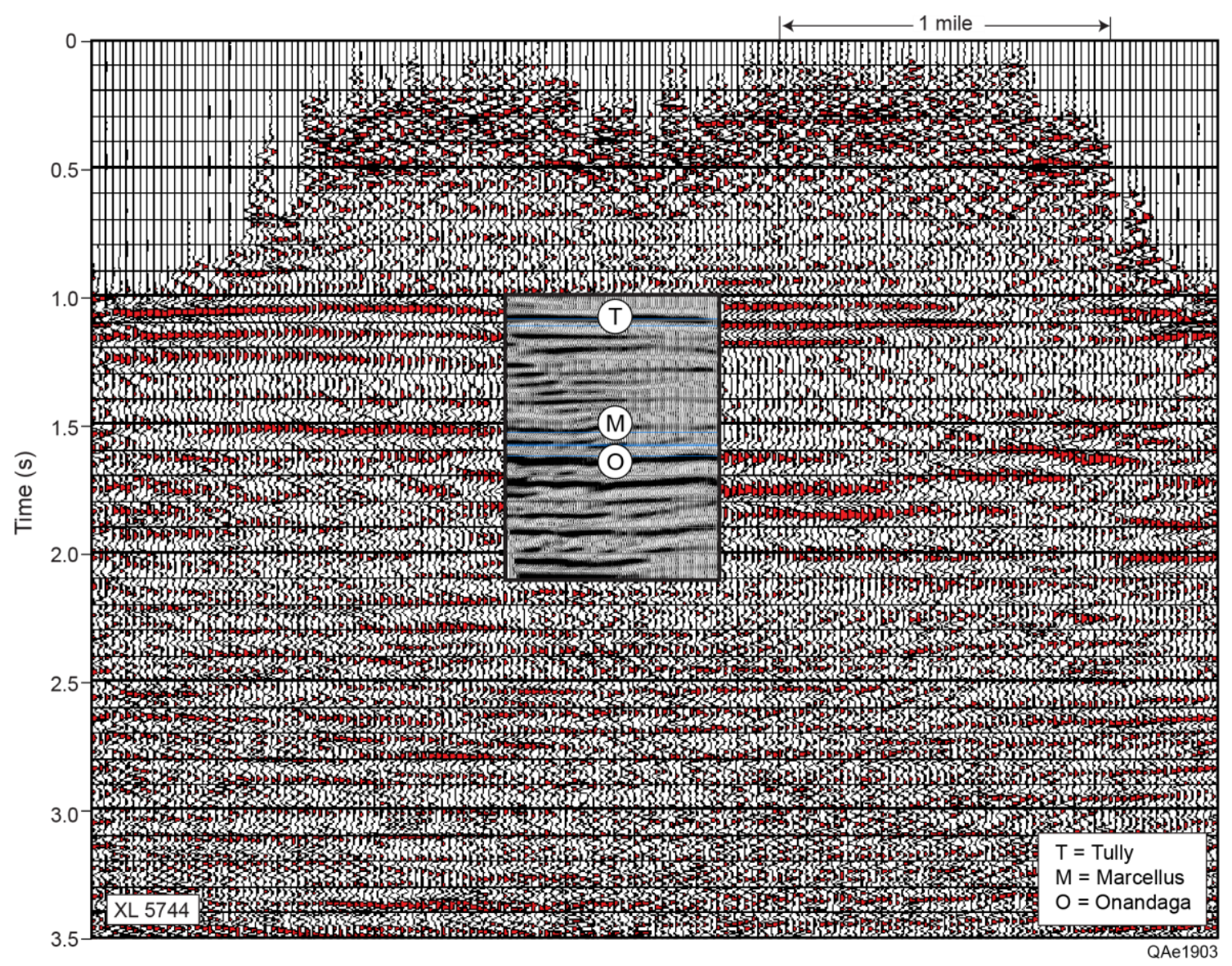

Figure 2. Comparison between the VSP S-S image created by a vertical vibrator (overlay) and an $S-S$ image created from shot-hole explosive data acquired around the VSP well. The VSP image is the S-S data window from Figure 1 that extends from $0.6 \mathrm{~s}$ to $1.3 \mathrm{~s}$ on the P-P image-time scale used in that figure. Here in this figure, the VSP S-S image is displayed at the same S-S vertical image-time scale used to display the shot-hole explosives S-S image. 
We show as Figure 2 a vertical slice through a brute stack constructed from the transverse-S data extracted from the surface-recorded shot-hole explosive data. We refer to this image as a brute stack because: (1) it was constructed with a single velocity function (no lateral velocity variations were allowed), (2) only one estimate of S-wave static corrections was calculated and applied to the data, and (3) we made no effort to rotate the data to natural earth coordinates that would allow fast-S and slow-S modes to be separated. As previously stated, we created this image in haste so we could provide DOE Geothermal our final report rebuttal as soon as possible.

In Figure 2 we compare this surface-based brute stack version of a transverse-S image with the VSP transverse-S image from Figure 1. The VSP image is time shifted to account for the fact that a different depth datum was used when processing the VSP data and the 3D data and is also stretched to the same S-S image-time scale used to display the surface-based image. No effort was made to equalize the basic wavelets in the two images to improve the phase alignments of events. The comparison between the two images is reasonable and implies our quickly constructed brute stack not only demonstrates direct-S modes are produced by vertical-force sources, but also confirms the software we developed in Phase 1 is adequate for generating S-S images from these direct-S data. An important point is that this image comparison shows that equivalent S-S images can be created by different types of vertical-force sources - shot-hole explosives (surface data) and vertical vibrator (VSP data).

The surface-based S-S image displayed in Figure 2 was created with the software and knowledge we created in Phase 1 of this project. Again, we claim the real-data evidence we show here is proof positive that the DOE Geothermal Review Panel not only erred, but were 100-percent wrong, in saying our research in Phase 1 would not succeed and was not worthy of continued funding, and in stating "other evidence or more convincing evidence is needed".

The images exhibited in Figure 2 are the first-ever versions of a 3D volume of S-S data produced from direct-S modes radiating from a vertical-force source. Nowhere in geophysical literature can DOE, or any geophysical peer reviewers, cite an example where anyone has ever made a 3D seismic data volume from direct-S modes produced by a vertical-force source. We will unfortunately publish this historic example with DOE Geothermal not being acknowledged because they have concluded the technology will not work and decided to abandon the development of this new S-wave imaging technology. 


\section{Approach 3 - SV-P Images from Surface-Recorded Data}

As we developed the technology to utilize direct-S modes produced by vertical-force sources, we became aware of the great importance of the SV-P mode that can be created from the downgoing direct-SV mode produced by vertical vibrators. We now conclude that SV-P data produced by a vertical-force source may have greater value than the S-S data produced by such a source. The reason is that SV-P data are recorded by a vertical geophone (because the upgoing mode is a $\mathrm{P}$ mode). Thus $\mathrm{S}$-wave information can be extracted from common, single-component, vertical-geophone, P-wave seismic data.

We show as Figure 3 the first-ever example of a SV-P image produced by a vertical-force source; the source being a vertical vibrator in this case. We emphasize these data were generated by a vertical-force source because our search of geophysical literature has uncovered only two studies where real SV-P data are exhibited and discussed (Fraiser and Winterstein, 1990; Guy, 2004). In each of these instances, the source used to generate the SV-P data was a horizontal vibrator, the classic horizontal-force source used to generate direct-S modes. Our research demonstrates it is not necessary to use a horizontal vibrator to create SV-P data.
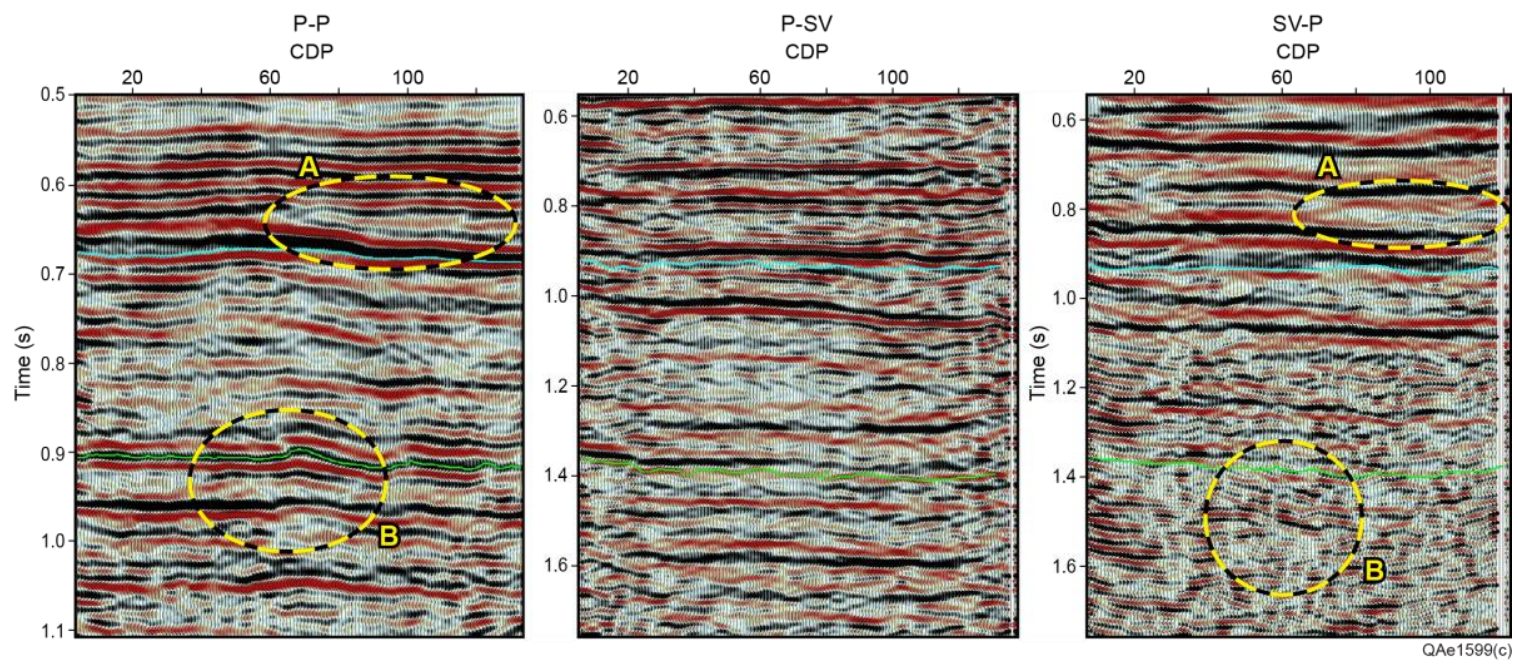

Figure 3. Comparison of P-P, P-SV, and SV-P images. (a) Features A and B in the P-P image are targets of interest. (b) Features $A$ and $B$ are not obvious on P-SV data. (c) Features $A$ and $B$ in SV-P image space have strong similarities to the $A$ and $B$ features in $P-P$ image space. In this instance there is greater confidence in the SV-P image than in the P-SV image.

Our SV-P image is compared with its companion P-P and P-SV images in Figure 3. This example is the third historic research product we are in the process of publishing. This research accomplishment could introduce a seminal change in the methodology the seismic community uses to acquire S-wave 
information because our technology introduces the possibility of creating S-wave information and S-wave images from common P-wave seismic data generated by a vertical-force source and recorded by vertical geophones. This application instantly makes thousands of square miles of legacy P-wave seismic data preserved in seismic data libraries available for $\mathrm{S}$-wave data processing. This processing of legacy P-wave seismic data will use the software we developed in Phase 1, which DOE Geothermal claimed had no likelihood of success. The Board of Regents of the University of Texas is already in discussions with two seismic data-processing companies about commercializing our SV-P technology.

The energy source used to acquire these data was a vertical vibrator. The data were acquired with $3 \mathrm{C}$ geophones because the operator desired to evaluate the prospect with both P-P and P-SV data. The image area was small and spanned approximately $4 \mathrm{mi}^{2}\left(10 \mathrm{~km}^{2}\right)$. After the P-P and P-SV data volumes were created, the operator allowed our research team to have access to the vertical-geophone data so that an SV-P data volume could be created.

In Figure 3, both converted-mode images (P-SV and SV-P) are squeezed vertically to be approximately depth equivalent to the P-P image. This image squeezing is illustrated by comparing the numerical labeling of the P-P time scale with the time scales of the P-SV and SV-P images. Unfortunately no VSP data were acquired within the image space to ensure precise depth calibration of the images. The two colored horizons shown on the seismic profiles are preliminary surfaces of investigation and have no depth-equivalent significance.

Two features of particular interest are circled on the P-P image. Feature A is a stratigraphic pinchout; feature $B$ is a structural element that creates a modest anticline. It is difficult to find equivalent features in the P-SV image. In contrast to the P-SV result, the two circled features on the SV-P image are reasonable approximations of features $A$ and $B$ in the $P-P$ image. Feature $A$ pinches out at approximately CDP 65 in both the P-P and SV-P images. Feature $B$ is dimmer in the SV-P image and seems to be shifted slightly to the left of its position in P-P image space. Based on this comparison of distinctive geologic targets, we conclude the SV-P mode provides a more reliable image of subsurface geology than does the P-SV image, the latter being the S mode that is currently utilized to evaluate geothermal prospects.

This SV-P imaging example is now being subjected to peer review by a geophysical journal. We expect publication of our SV-P technology development in 2014. We cannot credit DOE Geothermal for aiding the development of this new S-wave technology we produced with the software we developed in Phase 1 because DOE Geothermal has stated in writing that they have canceled our funding on the basis that the technology would not succeed. 


\section{Conclusion}

We have shown three examples that refute the logic of DOE Geothermal that the software we developed in Phase 1 of this project would not lead to successful image construction using direct-S modes produced by vertical-force sources.

Example 1 used VSP data to compare image quality of P-P and S-S modes produced simultaneously by a vertical vibrator. The high-quality images that resulted reverse the conclusion of the DOE Geothermal Review Panel that it was not advisable to use VSP data for to demonstrate direct-S applications.

Example 2 shows a hastily constructed S-S brute stack of direct-S modes produced by a vertical-force source. This surface-based image is compared with the VSP S-S image created in Example 1 to show the equivalence of the two approaches to producing S-S images with direct-S modes (VSP data vs. surfacebased data). Our surface-based S-S image was constructed with software we developed in Phase 1 that DOE Geothermal has stated in writing was expected to fail.

Example 3 is a spin-off application of our original objective to concentrate on S-S image with direct-S modes produced by vertical-force sources. Such spinoffs often occur when a well-conceived research program is executed. This new approach to constructing S-wave information for geothermal applications utilizes a converted-wave mode produced by direct-SV modes propagating from verticalforce sources. This converted wave is the SV-P mode generated by the downgoing SV mode produced, in this case, by a vertical vibrator. This SV-P mode allows an S-wave image to be created from P-wave seismic data, which is a capability that could revolutionize S-wave seismology. The software developed in Phase 1 was again used to isolate the direct-SV modes needed to create the SV-P image shown in Figure 3.

Our conclusion is that DOE Geothermal was influenced by the poor logic of the DOE Review Panel who appear to not have the technical knowledge needed to evaluate this new approach to generating fracture-sensitive S-wave information generated by vertical-force seismic sources. The imaging examples we show in this final report present proof that the DOE Review Panel was 100percent wrong in concluding our technology would not be successful and Phase 2 funding should thus be canceled. We have no objection to our research being canceled because of unavailable funds. We object strongly to any and all implications that our research was faulty and that our technology could not succeed. 


\section{List of Acronyms and Abbreviations}

direct-S: an S mode produced directly at the point where a vertical-force seismic source applies its force vector to the earth

P-P: a seismic wavefield created by a downgoing $P$ mode and an upgoing $P$ mode

P-SV: a seismic wavefield created by a downgoing P mode and an upgoing SV mode

S-S: a seismic wavefield created by a downgoing $S$ mode and the same upgoing $S$ mode

SV-P: a seismic wavefield created when a downgoing SV mode converts to an upgoing $\mathrm{P}$ mode

VSP: vertical seismic profile

\section{References}

Frasier, C., and D. Winterstein, 1990, Analysis of conventional and converted mode reflections at Putah sink, California using three-component data: Geophysics, v. 55, No. 6, p. 646-659.

Guy, E.D., 2004, Evaluation of near-surface converted-mode seismic reflection imaging potential: Electronic Journal of Geotechnical Engineering, v. 9, p 1-35. 
Appendix A

DOE No-Go Letter 


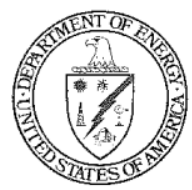

\section{Department of Energy \\ Golden Field Office \\ 1617 Cole Boulevard \\ Golden, Colorado 80401-3393 \\ June 11, 2013}

Dr. Bob Hardage

University of Texas at Austin

P.O. Box 7726

Austin, TX 78713-7726

SUBJECT: Phase 1 Go/No-Go Decision Point - DOE Award No. DE-EE0005512,

"Extracting And Applying A Seismic Wave Mode Involving A Downgoing Shear

Velocity Wave And An Upgoing Shear Velocity Wave From Vertical Vibrator

Data"

Dear Dr. Hardage:

The U.S. Department of Energy (DOE) Geothermal Technologies Office (GTO) conducted a Go/No-Go review of the above referenced award on May 7, 2013, pursuant to the Statement of Project Objectives (SOPO) and the Provision 1, "Continuation Application and Funding -

Awards Under 10 CFR 600" of the Special Terms and Conditions of the above referenced award. As reflected in the SOPO, the Go/No-Go review considered the sufficiency of Phase 1 software development and testing to determine whether the proposed technology has the potential for estimating and mapping fracture attributes across geothermal prospects. Specifically, the project had to meet certain milestones included in the SOPO. Federal funding beyond Phase 1 was contingent on (1) availability of federal funds; (2) meeting the objectives, milestones, deliverables, decision point criteria, and stage gates of the recipient's approved project and obtaining approval from DOE to continue work on the project; (3) submittal of required reports; and/or (4) compliance with the terms and conditions of the award.

DOE GTO conducted this review based upon the information in the Phase 1 Report for University of Texas at Austin (UT) that DOE received on February 22, 2013 and UT's presentation to the Go/No-go Review Panel. Based on the review and presentation, UT was unable to prove that the technology being tested had a reasonable likelihood of success. Further, UT failed to reach a critical milestone. In particular, there was no demonstration of the extraction of fracture attributes from direct S from P source data analyzed as part of UT's Phase I efforts.

The DOE appreciates your efforts to advance science by conducting research in seismic wave theory. In the current tight fiscal environment, DOE has limited funding to accomplish its strategic goals. Accordingly, based upon the outcome of the Go/No-Go review and the limited availability of federal funds, DOE GTO will not continue funding this project beyond Phase 1. 
University of Texas at Austin must provide the DOE with the final project deliverables, as laid out in your Federal Assistance Reporting Checklist, no later than September 5, 2013. Remaining DOE funds (if any) may be used for the wrap-up of the tasks under the approved Statement of Project Objectives, and preparing the final close-out documents. Should you have any questions, please contact the DOE Project Officer, Mark Ziegenbein, at (720) 356-1821.

Sincerely,

Luramenick

Laura Merrick

Contracting Officer

cc: David Hawkins, Recipient Business Officer

Mark Ziegenbein, DOE/GTO Project Officer

Eric Hass, DOE/GTO Hydrothermal Program Manager

Page 2 of 2 
Appendix B

Paper 1 Now in Peer Review 


\title{
Interpretation of Multicomponent Seismic Data across Wister Geothermal Field, Imperial Valley, California
}

Shuijian Wei ${ }^{1}$, Michael V. DeAngelo ${ }^{2}$, and Bob A. Hardage ${ }^{2}$

(1) Petroleum Exploration and Production Research Institute, Sinopec

(2) Bureau of Economic Geology, The University of Texas at Austin

\begin{abstract}
Multicomponent seismic technology has been implemented across Wister geothermal field in southern California to evaluate the potential for further development of geothermal resources. The seismic survey area was positioned atop the San Andreas fault system that extends southward from the Salton Sea. An interpretation of Wister Field geology was made using both P-P and P-SV seismic data. Two formation horizons: Canebrake/Olla/Diablo and Deguynos were interpreted. Seismic time-structure maps were generated for each horizon. The objective of the study was to determine whether productive geothermal resources could be detected and mapped more reliably with multicomponent seismic data than with single-component P-P data.

Complex faults associated with the regional San Andreas Fault system were interpreted across the $13.5 \mathrm{mi}^{2} 3-\mathrm{D}$ image space. The structural maps that were created are thought to be some of the most accurate depictions of subsurface structure that are publicly available in this area of the Imperial Valley. Particular attention was given to documenting faults that cut across deep strata. Both P-P and P-SV seismic show evidence of such deep faults.
\end{abstract}

Rock properties were analyzed from well logs. Log data showed that 
clastic rocks at this site exhibited measurable differences in $\mathrm{Vp} / \mathrm{Vs}$ velocity ratios for different rock types. Specifically, sand-prone intervals were associated with relatively low $\mathrm{Vp} / \mathrm{Vs}$ velocity ratios, and shale-dominated intervals had higher $\mathrm{Vp} / \mathrm{Vs}$ ratios. Using this rock physics behavior, $\mathrm{Vp} / \mathrm{Vs}$ values derived from seismic travel-time thicknesses were useful for recognizing lithological distributions and identifying favorable reservoir facies.

Seismic data across Wister field, like seismic data across many geothermal fields, have a low signal-to-noise character. We demonstrate that a unified and integrated interpretation of $\mathrm{P}$ and $\mathrm{S}$ data, even when seismic data quality is not as good as interpreters wish, can still yield valuable information for resource exploitation.

Keywords: multicomponent, interpretation, geothermal reservoir, Wister

\section{Introduction}

Conventional single-component seismic technology has been applied in geothermal exploration for more than 40 years. However, many geothermal reservoirs are composed of structurally deformed high-velocity rocks that can be influenced by high temperature steam, reservoirs systems often are beneath complex surface geology, and geothermal prospects commonly have large lateral changes in seismic wave velocities in their complex subsurface layering of hard and soft rocks. These factors combine to create low signal-to-noise P-wave seismic data. Even though multicomponent seismic technology is more attractive for geothermal reservoir characterization, lithologic identification, pore- 
fluid prediction, and fracture detection than is single-component P-wave technology, only a few studies have used multicomponent seismic technology to detect productive geothermal facies (Rial et al., 2005; Rabbel and Luschen, 1996; Lou and Rial, 1997). Our reason for publishing this work is to provide the geothermal development community a case history that documents comparative values of multicomponent and single-component seismic technologies.

Our study utilizes a 3-D converted-shear-wave (P-SV) project that was implemented by Ormat, the field operator, to reduce geothermal exploration risk at their Wister Field in the southern portion of the Imperial Valley of California. These data were acquired using vertical vibrator sources and single-point multicomponent (3-C) geophones. Ormat graciously allowed our research team to utilize these 3C3D seismic data and selected calibration logs to do a second interpretation of the data.

In this paper, a $13.5 \mathrm{mi}^{2} 3-\mathrm{D}$ multicomponent seismic data set located in the Imperial Valley of southern California is interpreted and analyzed with guidance provided by well logs acquired within the seismic image space. The objectives of this study are to interpret and assess potential reservoir units, characterize fault and fracture geometries, evaluate the potential for further development of geothermal energy, and determine what advantages multicomponent seismic data offer over single-component $\mathrm{P}$-wave data when characterizing geothermal reservoirs.

In our interpretation, we were guided by the principle that geothermal production tends to be directly related to fracturing. Production wells should 
therefore be sited near major faults or within areas where wellbores have a high probability of penetrating significant intervals of fractured strata. From a multicomponent 3-D seismic data interpretation perspective, the fundamental requirement for siting productive wells is to place a wellbore where seismic data infer significant stratal movement and distortion have occurred because such rock deformations are indirect, but valuable, indicators of fracturing.

\section{Regional Geology and Stratigraphy}

Our study site was located within a complex zone of strike-slip faulting and oblique crustal extension and compression that defines the tectonically active boundary between the North American plate and the Pacific plate in southern California as shown on Figure 1 (Dorsey, 2006). A generalized stratigraphic column for this area of the Imperial Valley is illustrated in Figure 2.

Wister field is located in a Cenozoic sedimentary basin. The lower part of the Neogene section is the Split Mountain Group, consisting of lower Miocene continental sandstones and conglomerates of the Red Rock Formation (Kerr and Kidwell, 1991; Winker and Kidwell, 1996). In some places, these strata are conformably overlain by volcanic basalts, breccias, and interbedded basalt-clast conglomerates of the Middle Miocene Alverson volcanics (Gjerde, 1982; Ruisaard, 1979; Kerr, 1982). The Upper Miocene section is the Latrania formation of the Imperial Group that conformably transitions from Split Mountain strata. The Latrania formation is conformably overlain by regionally extensive fine-grained marine deposits of the Deguynos formation (Winker and Kidwell, 1996; Remeika, 1995). Upper Pliocene strata contain the Palm Spring Group, 
composed of thick accumulations of non-marine sedimentary rocks that form the Canebrake/Olla/Diablo, Tapiado, and Hueso formations. Pleistocene strata were deposited as coarse non-marine sedimentary rocks.

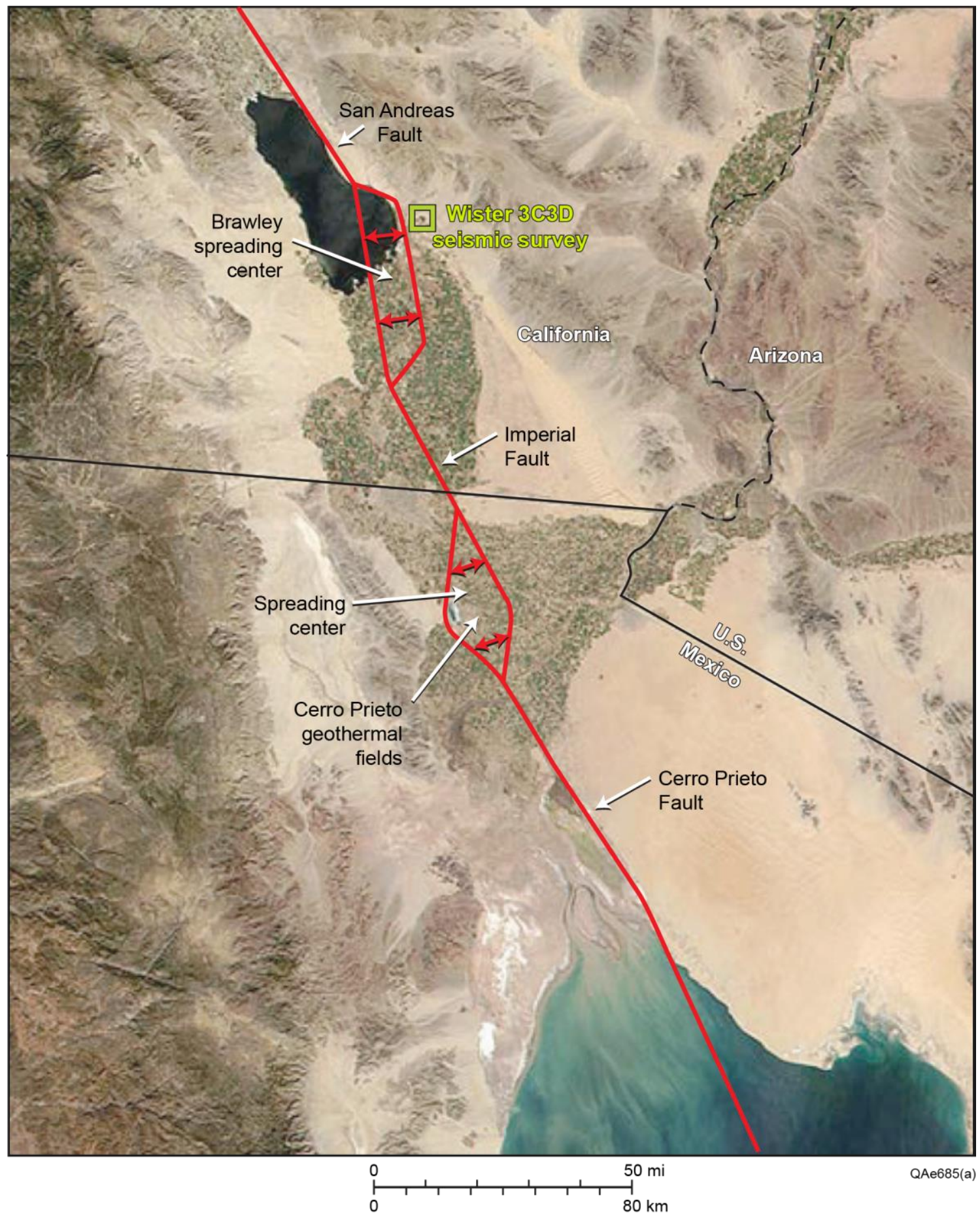

Figure 1. Location of Wister Field study area. 


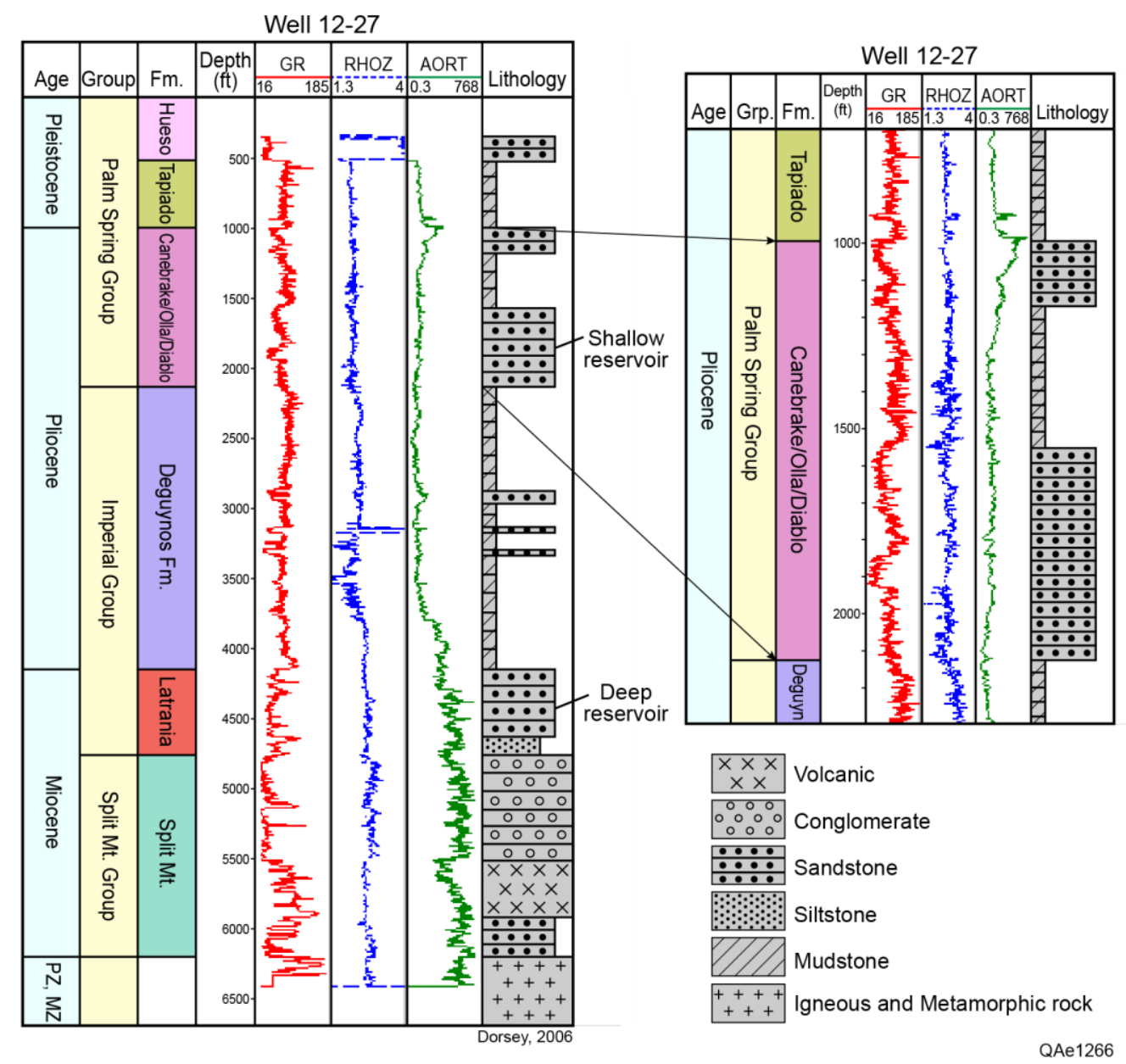

Figure 2. Stratigraphic column of the Imperial Valley (modified from Dorsey, 2006).

From lithology data interpreted from well 12-27 in Wister field (Fig. 2), there are two sandstone reservoir intervals of interest. The shallower reservoir, the Canebrake/Olla/Diablo sandstone formation, is approximately $170 \mathrm{~m}(558 \mathrm{ft})$ thick in well 12-27 with its top positioned at a depth of $488 \mathrm{~m}$ (1600 ft). The deeper sandstone reservoir interval spans the Latrania and Split Mountain formations. This second reservoir interval is interspersed over a rock layering more than $610 \mathrm{~m}(2000 \mathrm{ft})$ thick that starts at a depth of approximately $1280 \mathrm{~m}$ (4200 ft). In this paper, we will focus on the shallower Canebrake/Olla/Diablo formation. 


\section{Interpretation}

\subsection{Synthetic Seismograms and Correlation of Well Log and Seismic Data}

To define geological formation tops on seismic sections, it is essential to establish a reliable tie between well-based synthetic seismograms and seismic data local to a calibration well. For our calibration, we utilized a dipole sonic log acquired in well 12-27 inside the seismic image space in which data recording extended downward to the top of seismic basement. P-P and P-SV wavelets extracted from seismic data at the 12-27 well location were combined with $V_{P}$ and $V_{S}$ velocities measured from these dipole log data to generate P-P and P-SV synthetic seismograms for seismic interpretation purposes.
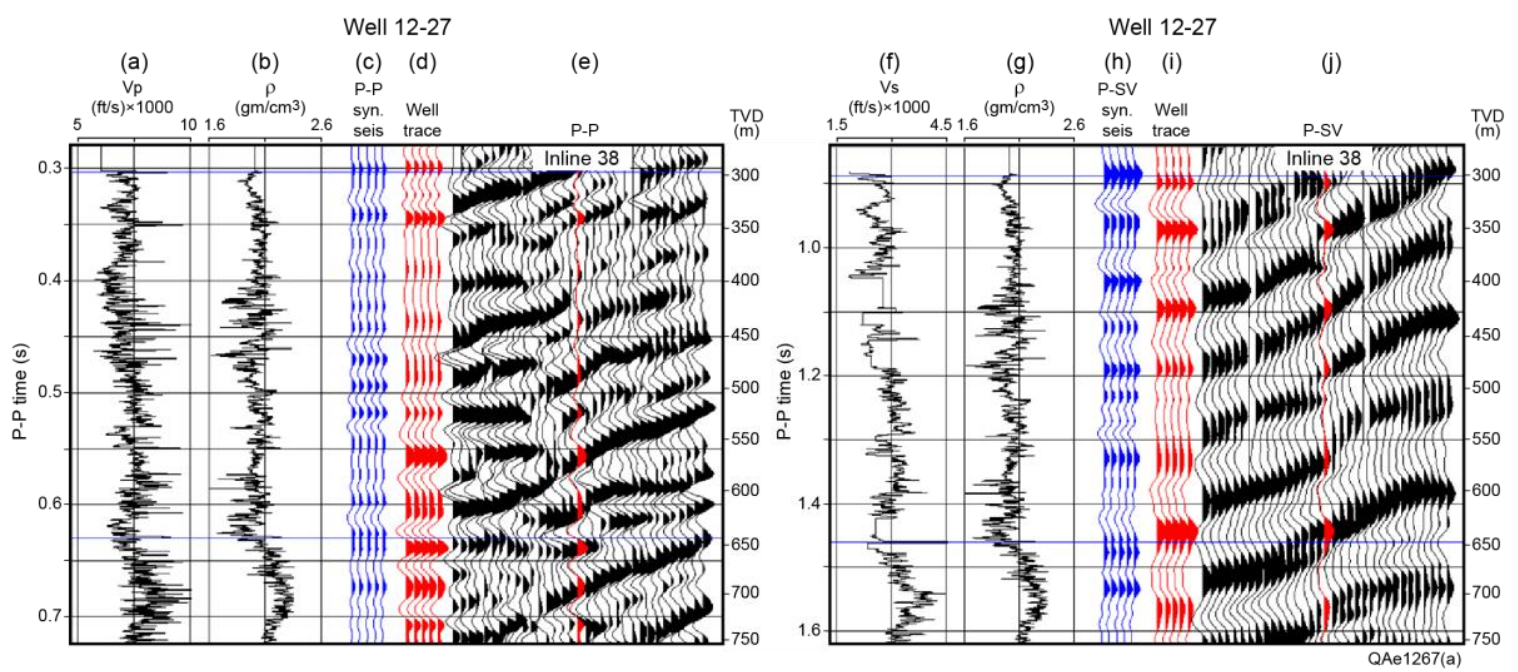

Figure 3. (a) Vp log, (b) Bulk density, (c) P-P synthetic seismogram, (d) P-P seismic trace at well 12-27, and (e) P-P profile seismic across well 12-27. ( $f$ through $j$ ) Same sequence of data for PSV data. No stretch or squeeze is applied to the synthetic seismograms.

The P-P synthetic seismogram from well 12-27 (Fig. 3c) was compared with migrated P-P data local to the well (Fig. 3d) to develop correlations between geological formations and P-P seismic events. Visual inspection of Figure 3 shows the registration of the P-P seismogram with the migrated $\mathrm{P}-\mathrm{P}$ data is not 
ideal, but the synthetic seismogram did provide valuable guidance for picking P-P reflection events that corresponded to, or closely approximated, targeted formation tops. This seismic calibration strategy led us to position the top of the Canebrake/Olla/Diablo formation on a strong peak of the 12-27 well trace at a PP time of approximately $300 \mathrm{~ms}$ and the top of the Deguynos formation at a reflection peak positioned at approximately $630 \mathrm{~ms}$ (Fig. 3e).

A P-SV synthetic seismogram was generated in P-SV image-time coordinates using $V_{P}$ and $V_{S}$ velocities measured from dipole sonic log data acquired in the 12-27 well. Because a P-to-SV reflection coefficient is zero at normal incidence (by definition), a P-SV synthetic seismogram was constructed by allowing small values of non-normal incidence and summing P-to-SV reflection magnitudes over a narrow range of near-vertical incidence angles. As was the case with the P-P synthetic seismogram, the agreement between the PSV synthetic seismogram and actual P-SV data was not ideal, but the P-SV seismogram still provided guidance about where to position key stratigraphic interfaces in P-SV migrated data. Using the P-SV synthetic seismogram as a guide, we placed the top of the Canebrake/Olla/Diablo Formation at approximately $900 \mathrm{~ms}$ on the 12-27 well trace in P-SV image space and the top of the Deguynos Formation at approximately $1460 \mathrm{~ms}$ (Fig. 3). The correlations between geological formation boundaries and seismic reflection surfaces were determined by comparing synthetic seismograms and seismic profiles (Fig. 4). 
Well 12-27

Zoeppritz Seismograms

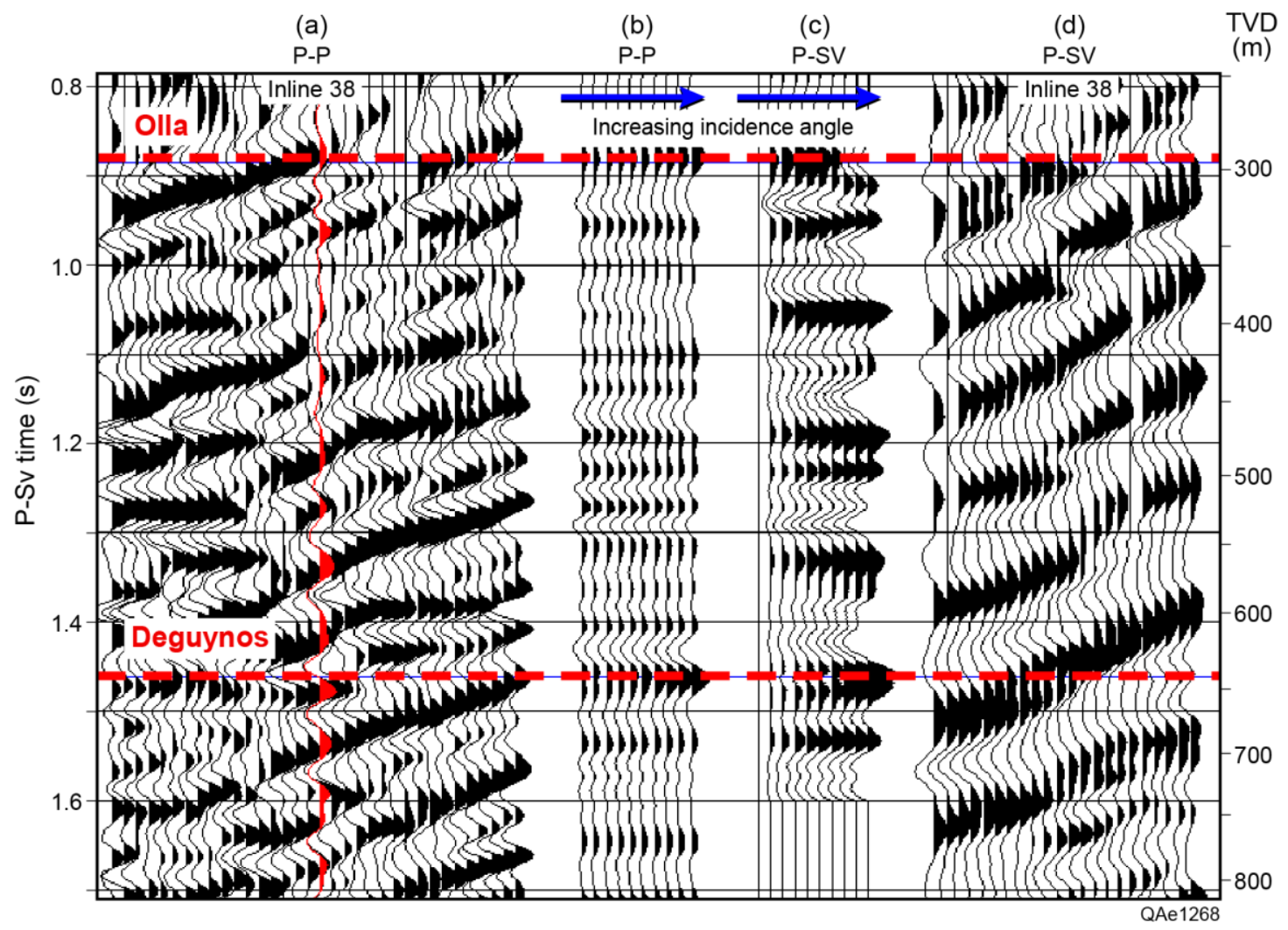

Figure 4. (a) P-P profile across well 12-27, (b) P-P synthetic seismogram, (c) P-SV synthetic seismogram, (d) ) P-SV profile across well 12-27.

\subsection{Depth Registering P-SV and P-P Seismic Data}

To directly compare P-SV data with P-P data, an interpreter needs a reliable technique that converts P-SV image time to P-P image time. We used the equation,

$$
\frac{\Delta T_{p s}}{\Delta T_{p p}}=0.5 \times\left(1+\frac{V_{p}}{V_{s}}\right)
$$

to relate P-SV image time at depth Z to P-P image time at that same depth (Hardage, et al., 2011). At Wister field, the $V_{P} / V_{S}$ velocity ratio can be calculated from $V_{P}$ and $V_{S}$ dipole log data to provide a calibration curve that allows an 
acceptable depth registration of P-SV to P-P image volumes across intervals of interest.

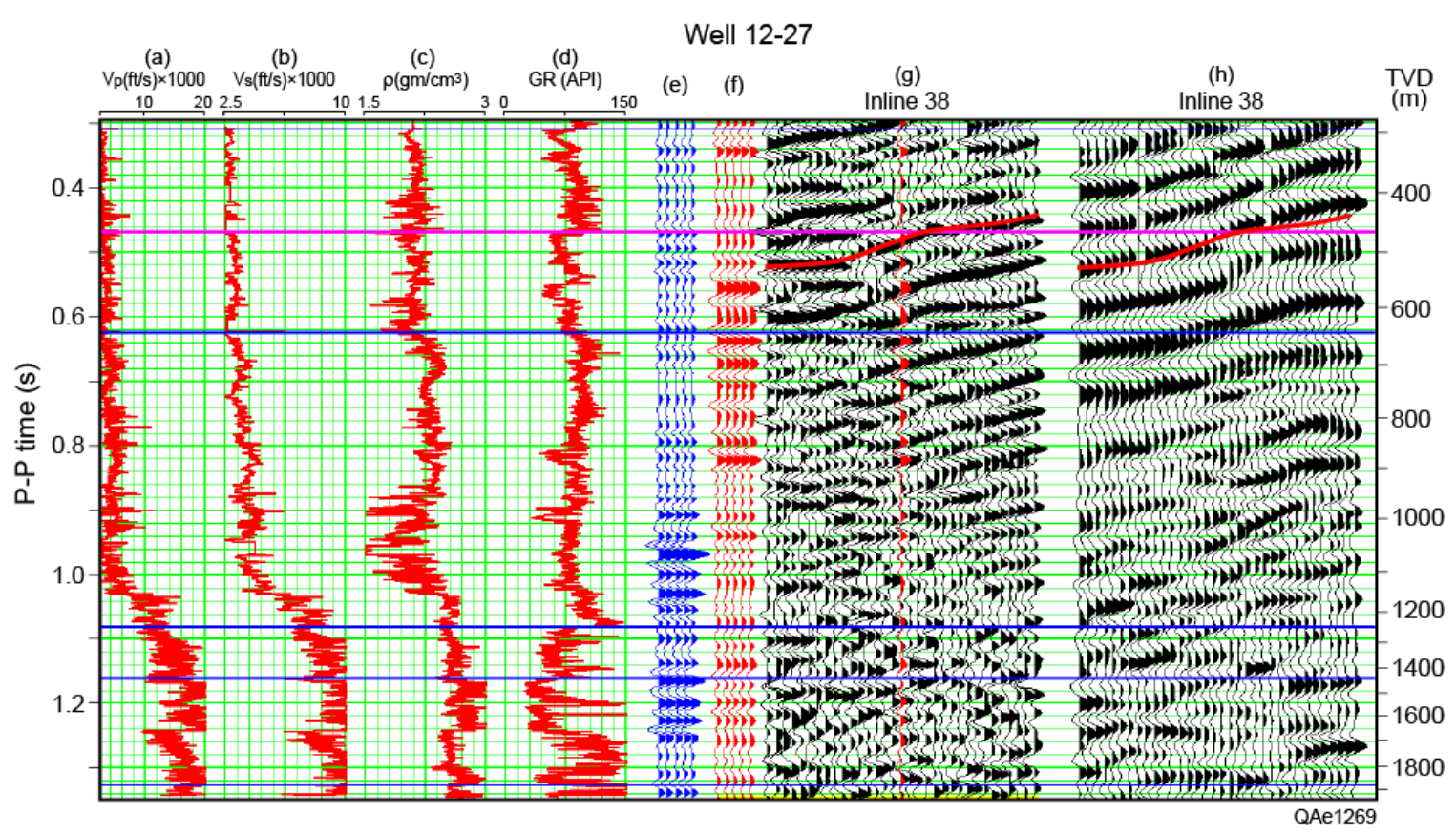

Figure 5. Unstretched and unsqueezed P-P seismic data and P-P synthetic seismogram displayed with a time-squeezed P-SV seismic section created using a log-based $\mathrm{Vp} / \mathrm{Vs}$ velocity ratio. The data are adjusted to a depth datum of $460 \mathrm{~m}$. The interpreted P-P structure (red dashed line) is superimposed on the P-SV data to illustrate the structural similarity of the two images.

From our calibration data, a strong reflection peak at $470 \mathrm{~ms} \mathrm{P}-\mathrm{P}$ time and 1200 ms P-SV time correlates to a depth of approximately $460 \mathrm{~m}$ at the $12-27$ calibration well. Reflections at these depths are important in our interpretation because they correspond to a deeper sand zone of the Canebrake/Olla/Diablo formation that has attractive properties for a geothermal reservoir. The correlation between P-P and P-SV data that have been adjusted to depthequivalent images for this reservoir target are illustrated on Figure 5. The P-SV profile obviously has reduced frequency content compared to the P-P profile (However, this does not mean P-SV data have longer wavelengths!), but the structural configuration of the strata is reasonably consistent in P-P and P-SV image spaces. 
The structural equivalence of P-P and P-SV images can be illustrated by overlaying interpreted P-P interfaces on the P-SV data (for example, the red dashed line in Figure 5). This interpretation strategy shows there are slight differences between time horizons from P-P seismic data and P-SV seismic data. Some of this difference is caused by using a spatially invariant $\mathrm{Vp} / \mathrm{Vs}$ ratio function to register P-SV and P-P seismic volumes when in fact $\mathrm{Vp} / \mathrm{Vs}$ changes across the image space. Nevertheless, the small differences between time horizons in P-P and P-SV seismic volumes shows that many geothermal reservoir intervals can be identified and characterized by $\mathrm{Vp} / \mathrm{Vs}$ ratios even when data quality is poor. A wider view of depth-registered data across the shallow reservoir interval is displayed as Figure 6.
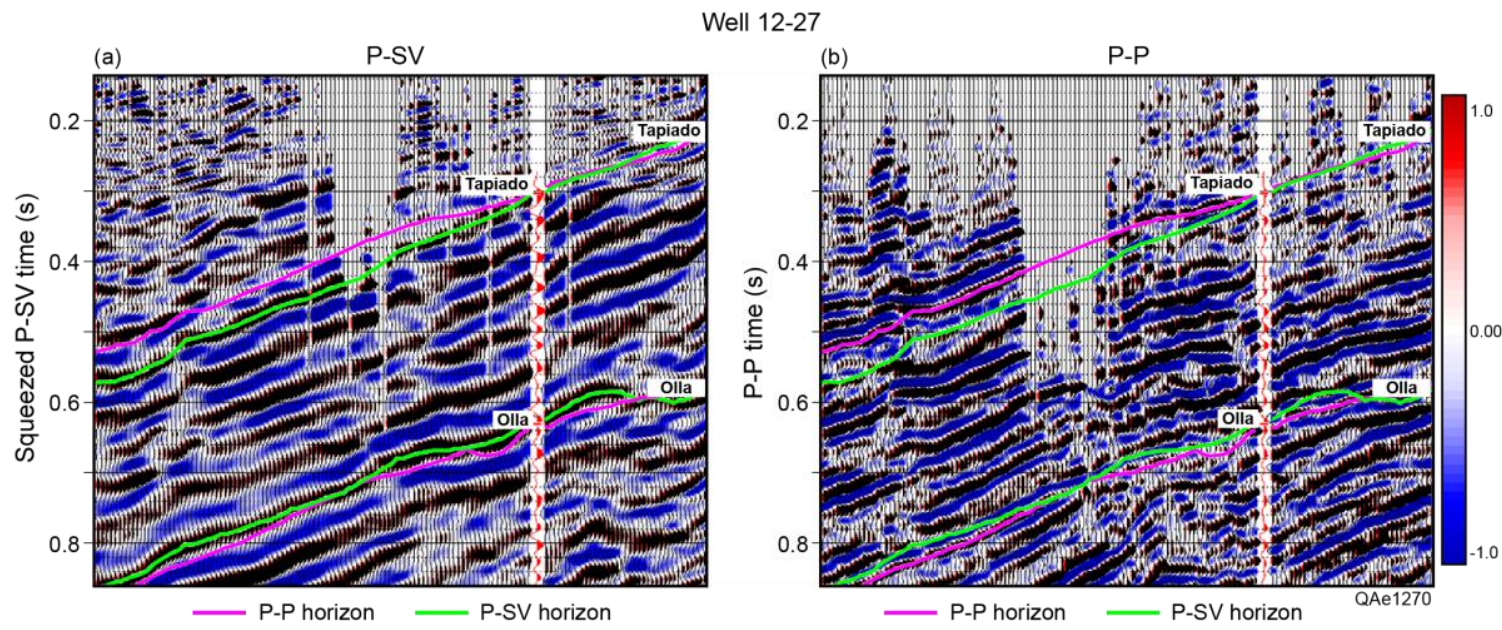

Figure 6. (a) Unsqueezed P-P seismic profile and (b) a time-squeezed P-SV seismic profile across well 12-27. The magenta line is an interpreted horizon in the P-P seismic data. The green line is the depth-equivalent interpretation of the same horizon in P-SV seismic data. 


\subsection{P-P and P-SV Data Interpretation}

Two horizons - the tops of Canebrake/Olla/Diablo and Deguynos formations - were picked in the data volumes, and their time-structure maps are shown on Figure 7. The structural trends shown on the P-P and P-SV timestructure maps are similar. Strata to the northeast are higher than to the northwest, and formation dip is southwest. Fault orientations are reasonably consistent and tend to trend northwest to southeast. P-P and P-SV fault configurations in some locations have different trends (Figure 8). The comparisons in Figure 8b show P-SV seismic data have a better signal-to-noise ratio than do P-P data. As a result, horizons and faults can be identified and interpreted more confidently in P-SV seismic data. Figure 8a shows there are apparent vertical displacements and sharp bends in horizons in P-SV sections that are not as obvious in P-P sections. Locations where such differences were noted are indicated by circled faults on the P-SV maps in Figure 7. 

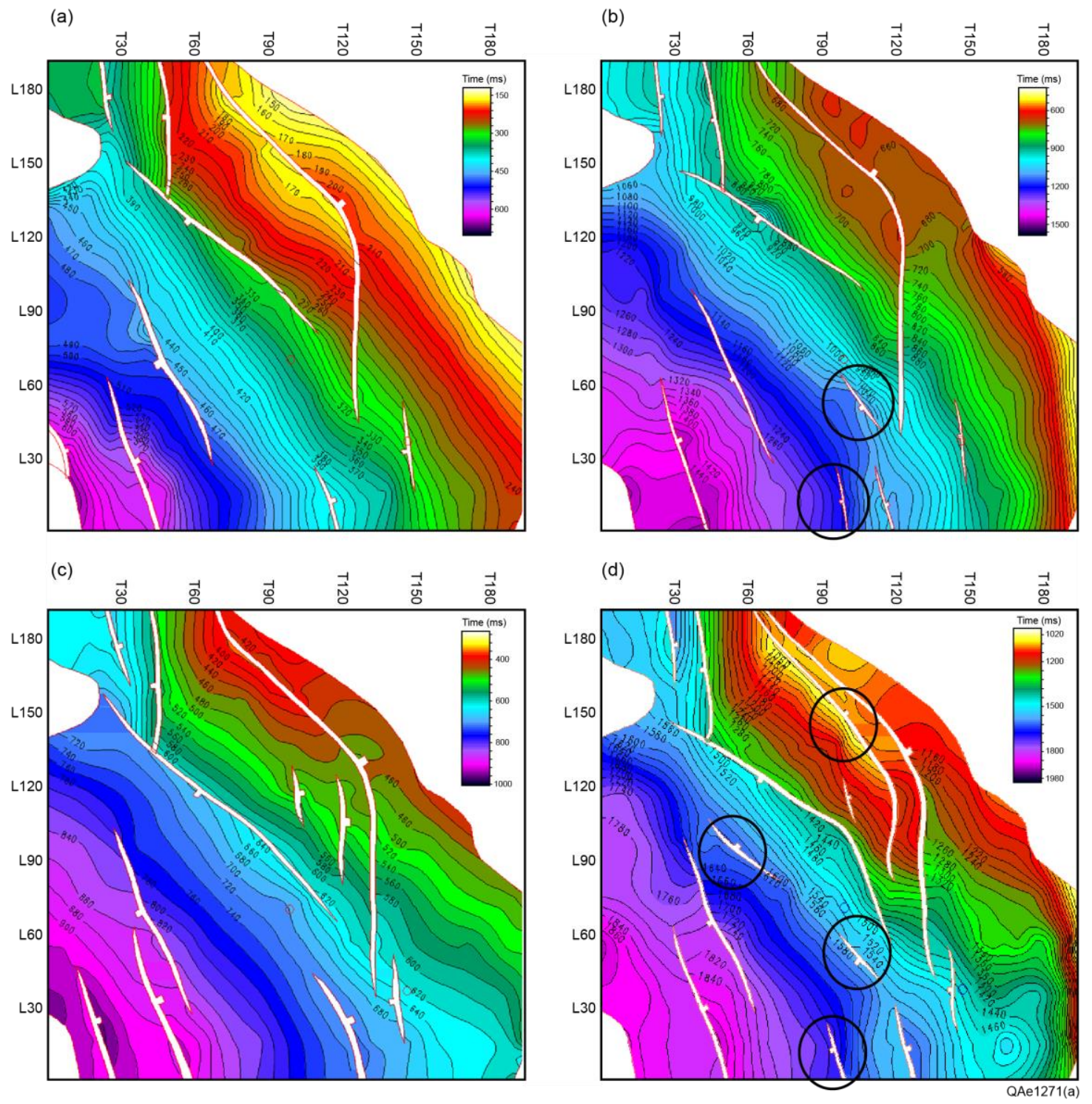

Figure 7. (a) P-P time-structure map of the Canebrake/Olla/Diablo horizon, (b) P-SV timestructure map of the Canebrake/Olla/Diablo horizon, (c) P-P time-structure map of the Deguynos horizon, (d) P-SV time-structure map of the Deguynos horizon. The circles mark locations where P-SV data show fault evidence that cannot be found in P-P data. 

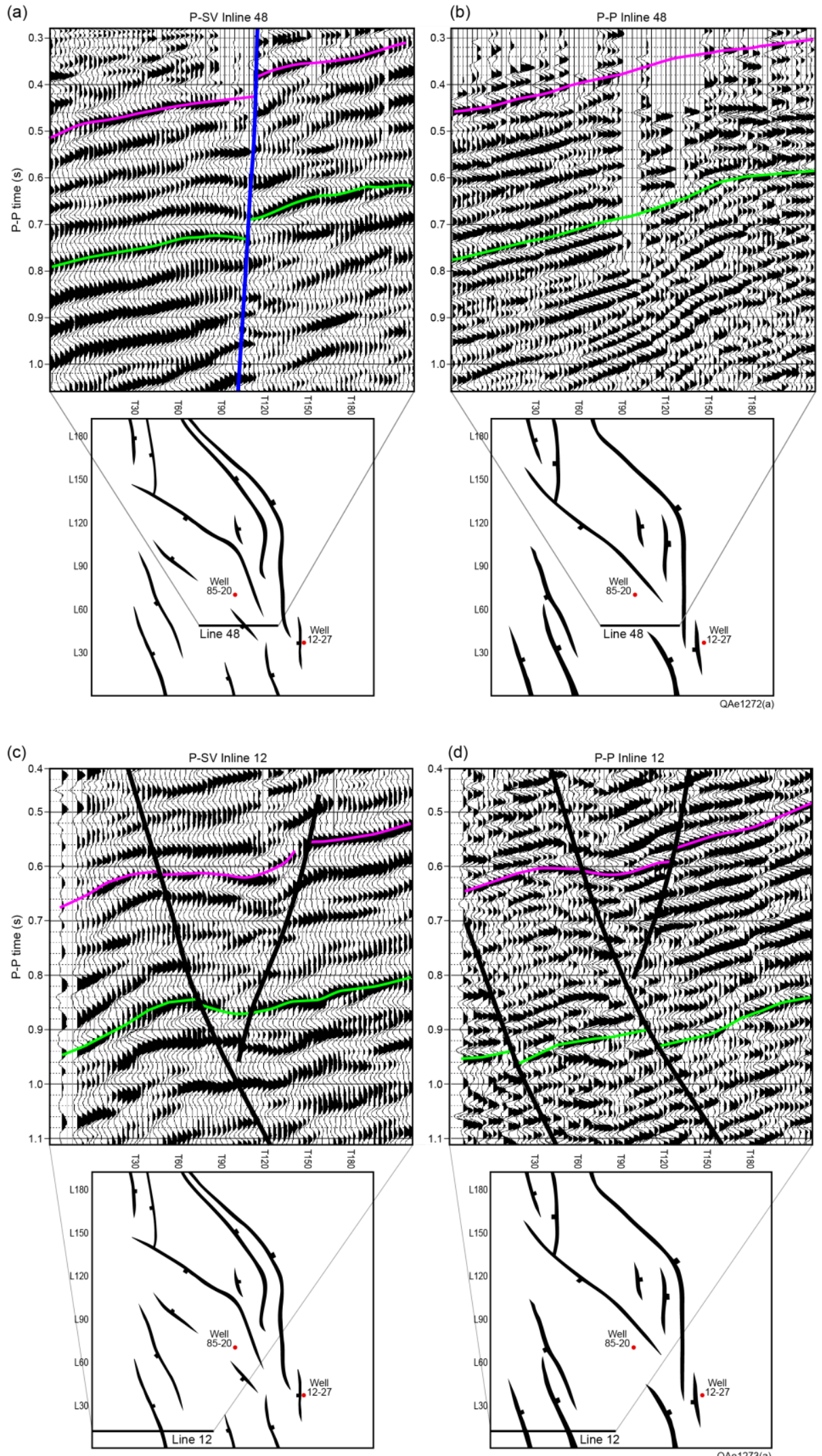

Figure 8. (a) P-SV section along inline 48. (b) P-P seismic section along inline 48. (c) P-SV section along inline 12. (d) P-P seismic section along inline 12. 
Our interpretation of these seismic data causes us to conclude most faults in the northeast part of the image space are detachment faults. These faults extend downward to the top of seismic basement, are low-angle normal faults in their early stages, and have increasing throw with the deposition of overlying sediments. Detachment faults in the west activated earlier than those in the east. However, the east detachment faults moved over a longer time period and thus affect shallower strata. Faults dipping southwest are adjustment faults that were activated in Pliocene time (Figure 9). 


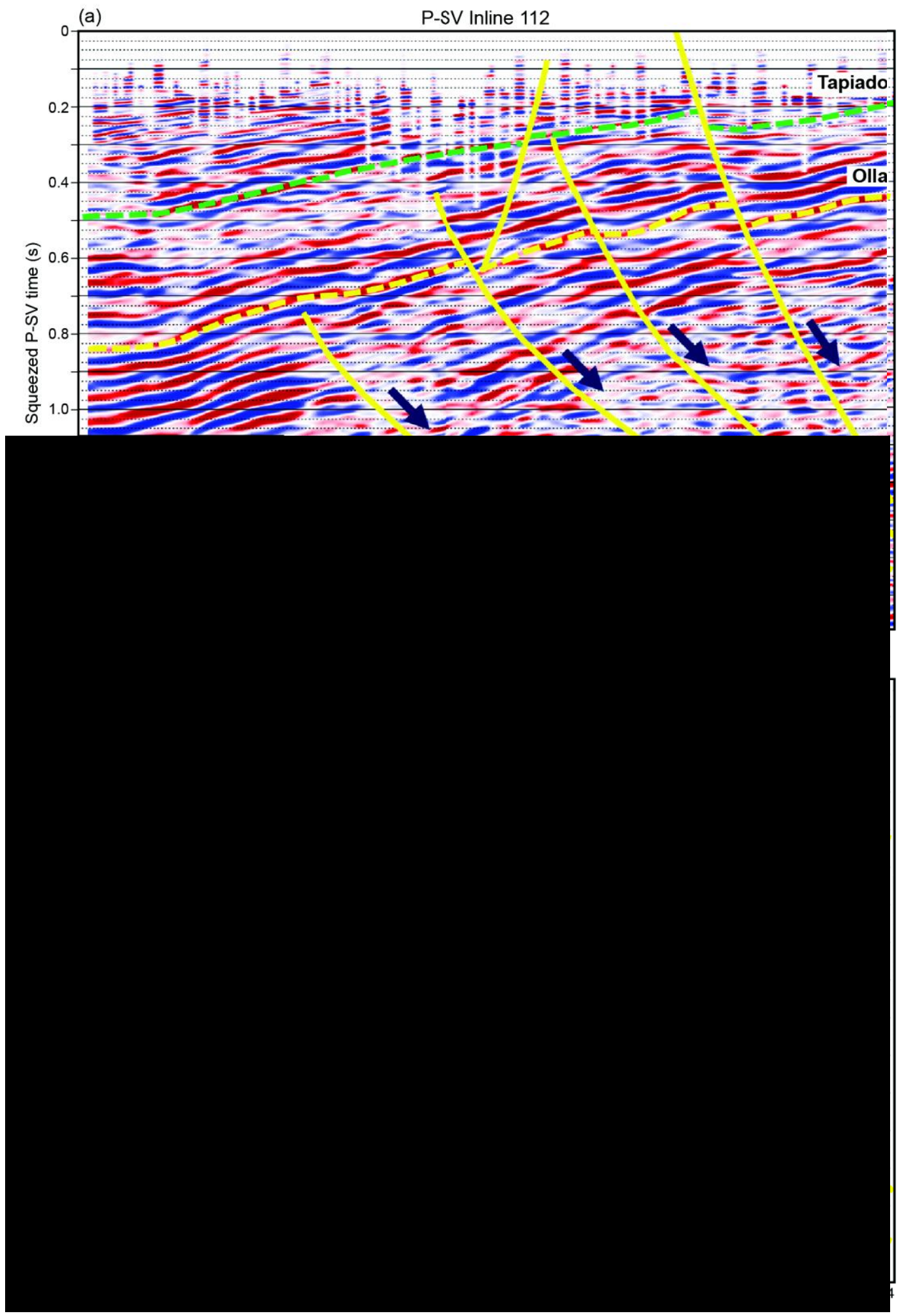

Figure 9. (a) P-SV interpreted section (b) P-P interpreted section. Inset maps show faults affecting the yellow-dash (Olla) horizon. 


\subsection{Rock Properties}

P-wave and S-wave velocities within different lithologies were analyzed using a dipole sonic log acquired in well 12-27 of Wister field. For the Canebrake/Olla/Diablo formation, clean sandstones have gamma-ray values ranging from 45 to $70 \mathrm{API}, \mathrm{P}$-wave slowness of $142-170$ us/ft, and S-wave slowness ranging from 375-500 us/ft. In contrast, mudstones have gamma-ray values ranging from 70 to $100 \mathrm{API}, \mathrm{P}$-wave slowness of 104-142 us/ft, and Swave slowness of 270-375 us/ft (Figure 10). For the Split Mountain formation, clean sandstones have gamma-ray values ranging from 20 to $60 \mathrm{API}, \mathrm{P}$-wave slowness extending from 45-58 us/ft, and S-wave slowness of 78-100 us/ft. Volcanic rocks in this same interval have gamma-ray values ranging from 70 to 100 API, P-wave slowness of 58-85 us/ft, and S-wave slowness of 100-160 us/ft.
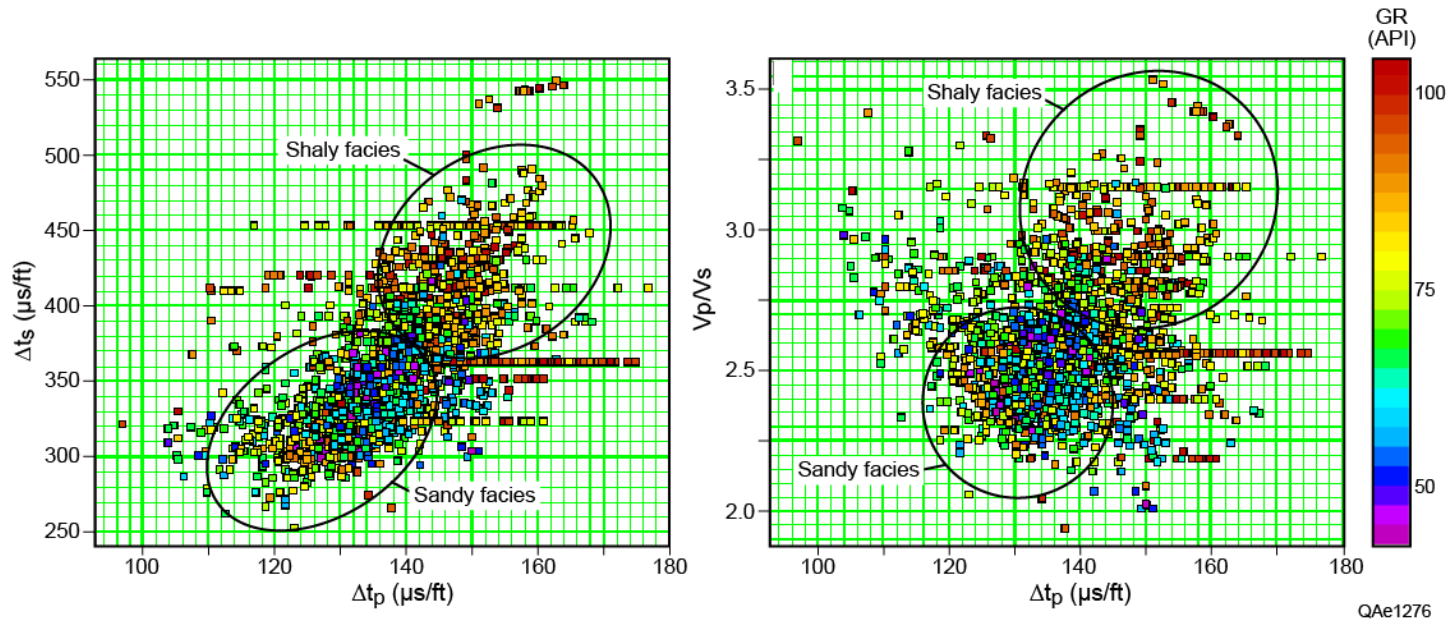

Figure 10. (a) Crossplot map of Vp versus Vs over the interval from 990 to $2121 \mathrm{ft}$ (302 to $646 \mathrm{~m}$ ) of well 12-27, (b) Crossplot of Vp versus Vp/Vs over the same interval.

Crossplots of $\mathrm{P}$-wave and S-wave velocities and $\mathrm{Vp} / \mathrm{Vs}$ ratios are shown in Figure 10. Over the interval from $990 \mathrm{ft}$ to $2121 \mathrm{ft}$, the $\mathrm{Vp} / \mathrm{Vs}$ value ranges from 2 
to 3.5. The good reservoir of the Canebrake/Olla/Diablo formation has a low $\mathrm{Vp} / \mathrm{Vs}$ value (2 to 2.6). In contrast, mudstones have a relatively high $\mathrm{Vp} / \mathrm{Vs}$ value (2.6 to 3.5$)$.

\subsection{Vp/Vs Map and Lithology Interpretation}

An average $\mathrm{Vp} / \mathrm{Vs}$ ratio map of the Canebrake/Olla/Diablo formation was computed from P-P and P-SV travel times across the interval between the Canebrake/Olla/Diablo and Deguynos using the following equation (Xu and Stewart, 2004):

$$
V_{p} / V_{s}=\frac{2 * \Delta T_{p s}}{\Delta T_{p p}}-1
$$

Figure 11 shows that this $\mathrm{Vp} / \mathrm{Vs}$ ratio changes across the seismic image space. The regions where the $\mathrm{Vp} / \mathrm{Vs}$ ratio is less than 2.6 are located in the southwest portion of the Wister seismic grid and are interpreted as areas of sandstone enrichment, which would be locations of favorable geothermal reservoir facies. 


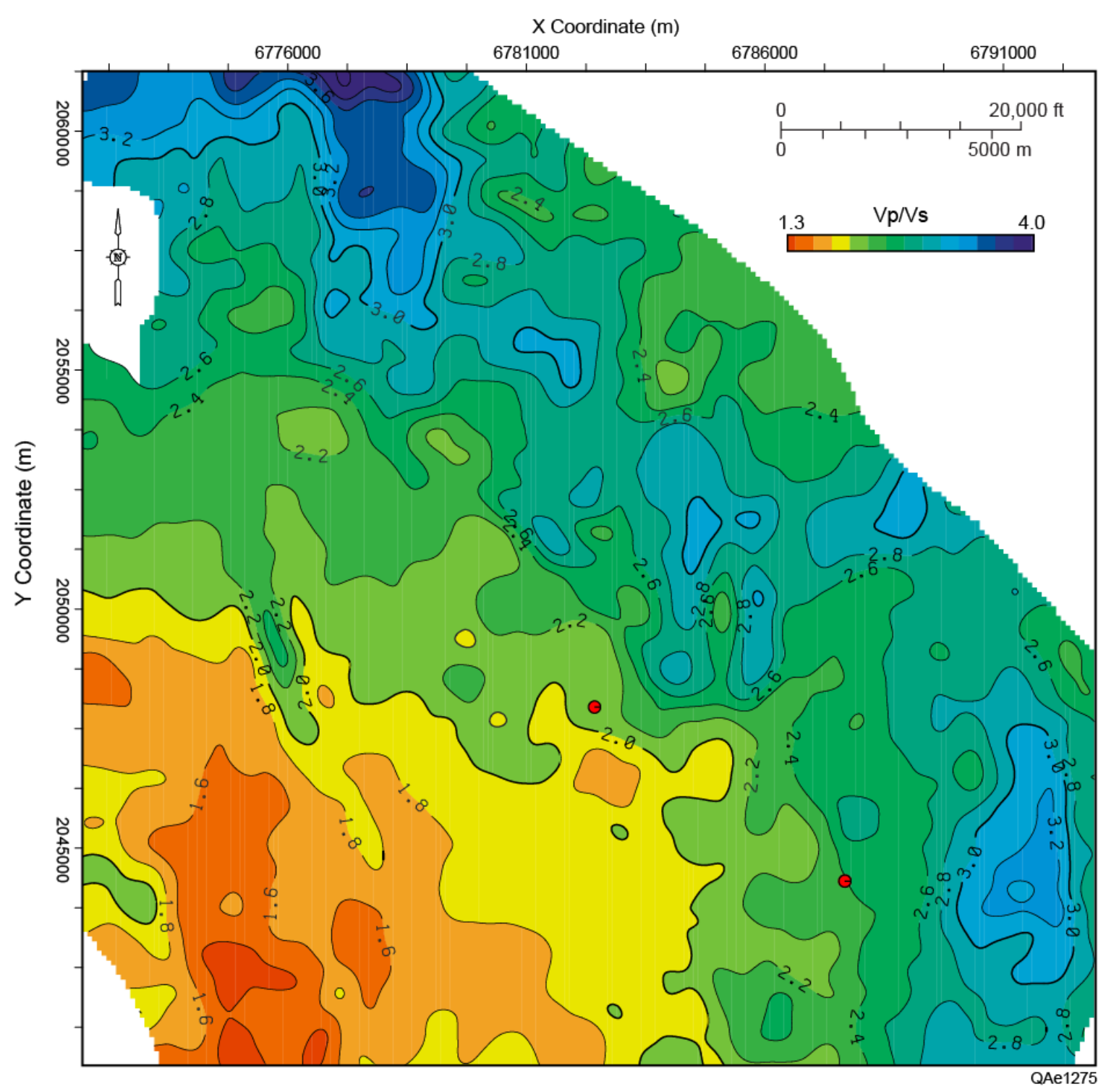

Figure 11. Map of $\mathrm{Vp} / \mathrm{Vs}$ values measured between the Canebrake/Olla/Diablo and Deguynos horizons.

\subsection{Curvature Attribute Analysis}

Curvature attributes were calculated from P-P and P-SV data to identify areas and zones that were most likely to be fractured. The trends of curvature values in both seismic volumes were dissimilar. Warm colors on the maps displayed as Figure 12 indicate higher likelihoods of fracture occurrence. 
Curvature values calculated from P-P data show a random distribution of strong warm colors in the northeast portion of the study area. Although this erratic curvature could suggest a strong likelihood of shattered rock and fracture development in this part of Wister field, inspection of the P-P seismic data showed these curvature values were significantly affected by the low signal quality of P-P data in the northeast portion of the image space. We tentatively concluded that the lowered P-P signal quality and the erratic P-P curvature values associated with reduced P-P signal may be caused by steam occupying a small percentage volume of the pore space in rocks in the northeast region of the seismic image space. Steam saturation as low as 5-percent of the void space of rocks can have a profound effect on P-P data. In contrast, the effect of steam (gas) saturation on P-SV data is much less.
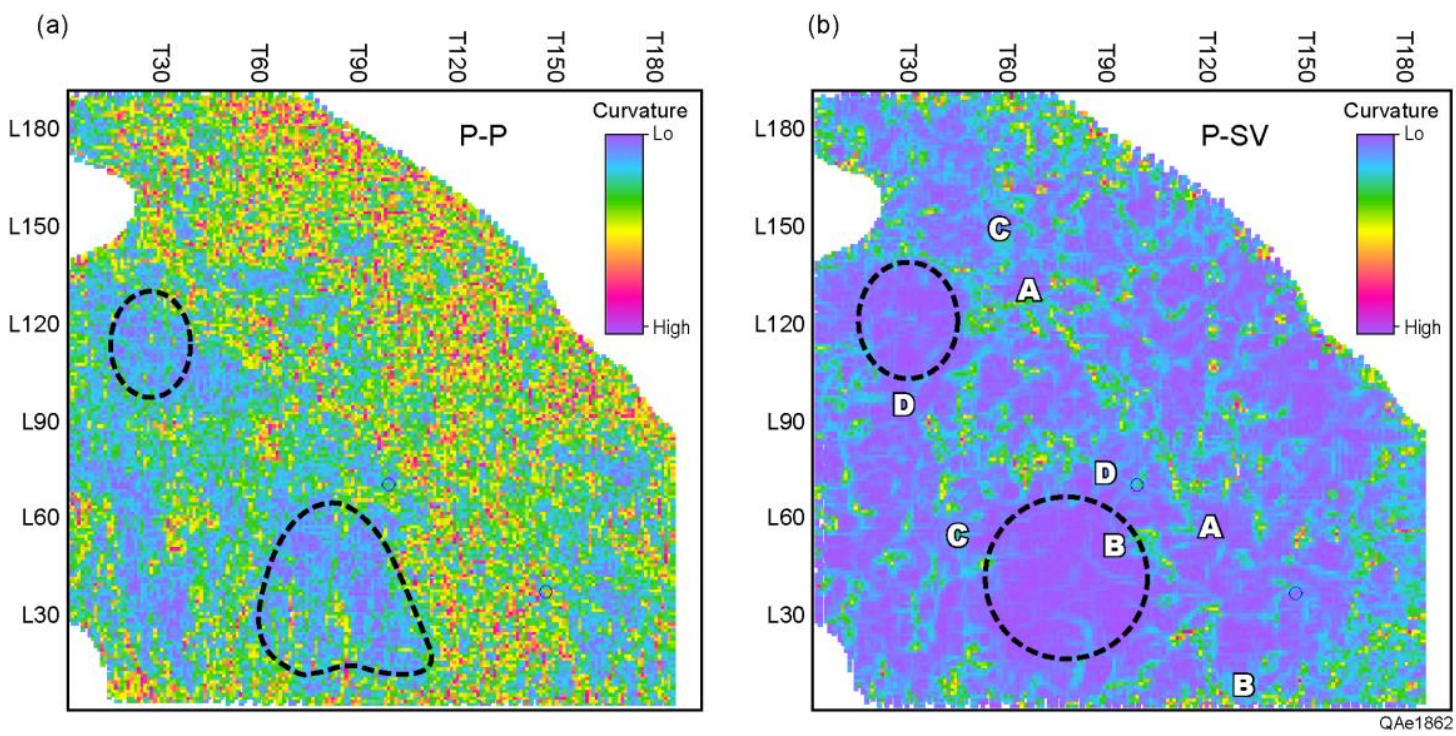

Figure 12. (a) Maximum positive curvature value calculated from P-P data over the interval from 990 to $2121 \mathrm{ft}$ (302 to $646 \mathrm{~m}$ ) of well 12-27, (b) Maximum positive curvature value calculated from P-SV data over the same interval. Note that P-P curvature is a distribution of random dots, but $\mathrm{P}$ SV curvature is more organized and often follows narrow trends that appear to be realistic maps of fault trends. The areas enclosed with dashed lines should have low fracture populations. 
An attraction of the P-SV curvature behavior (Fig. 12b) is that there are several narrow continuous trends of red/yellow (warm) curvature values that are quasi-linear or arcuate as an interpreter would expect fault trends to be in map view. Some of the more obvious of these trends are labeled AA, BB, CC, and DD. The areas enclosed by the dashed lines have minimal curvature and should not have large fracture populations. The mild curvature in these areas is again easier to interpret from the P-SV data than from the P-P data. In short, we conclude P-SV data are more sensitive to fractured intervals and subtle faults than are P-P data, especially so if the fractured rocks are invaded by hot steam. This characteristic of S-wave data increases the value of multicomponent seismic data for interpreting geothermal reservoirs.

\section{Conclusions}

We conclude multicomponent seismic data are preferred over singlecomponent P-wave seismic data for evaluating geothermal resources. P-P and P-SV images can be interpreted jointly to delineate structure, stratigraphy, and fault systems. Vp/Vs values computed from time-thickness ratios are particularly useful for predicting rock type as well as for delineating reservoirs. This valuable rock attribute $(\mathrm{Vp} / \mathrm{Vs})$ cannot be constructed unless S-wave seismic data are available. Anomalies interpreted from curvature maps show that P-SV data yield more realistic pictures of fault systems and fracture trends than do P-P data. This observation is particularly true when $\mathrm{P}$ and $\mathrm{S}$ wavefields may be propagating through a medium where there is a low concentration of gas (or steam) in the 
pore spaces of the rocks. We recommend P-P and P-SV curvature maps be created to aid the identification of subtle faults and fracture swarms in geothermal systems.

\section{Acknowledgements}

This study was funded by the U.S. Department of Energy as a work task in contract EE0005512. The Bureau of Economic Geology acknowledges support of this research by Hampson-Russell Software Services and Landmark Graphics Corporation who donated the software used in the interpretation. The authors thank Ormat for providing access to the data that were utilized in this study. The lead author was a Visiting Scholar to the Exploration Geophysics Laboratory for 12 months and thanks Dr Hardage for his constructive review and comments that clarified many points of multicomponent seismic interpretation and also thank Rui Zhang and Dallas Dunlap for their technical support. All authors thank Ormat for providing access to the data that were utilized in this study.

\section{References}

Dorsey, R. J., 2006, Stratigraphy, tectonics, and basin evolution in the AnzaBorrego Desert region. Fossil Treasures of the Anza-Borrego Desert, p. 89-104.

Gjerde, M. W., 1982, Petrology and geochemistry of the Alverson formation, Imperial County, California. Master of Science Thesis, San Diego State University, 85 p. 
Hardage, B. A., M. V. DeAngelo, P. E. Murray, and D. Sava, 2011, Multicomponent seismic technology, Geophysical References Series No. 18, Society of Exploration Geophysicists, Tulsa, OK, 318 pages.

Kerr, D. R., 1982, Early Neogene continental sedimentation, western Salton Trough, California [M.S. thesis]. San Diego State University, San Diego, California, $138 \mathrm{p}$.

Kerr, D. R., and Kidwell, S. M., 1991, Late Cenozoic sedimentation and tectonics, western Salton Trough, California. In Walawender, M. J., and Hanan, B. B., (eds.), Geological Excursions in Southern California and Mexico. Department of Geological Sciences, San Diego State University, San Diego, California, p. 397416.

Lou M. and J. A. Rial, 1997, Characterization of geothermal reservoir crack patterns using shear-wave splitting, Geophysics, Vol. 62, Issue 2, pp.487-494

Rabbel,W and Lüschen,E., 1996, Shear wave anisotropy of laminated lower crust at the Urach geothermal anomaly, Tectonophysics, Vol. 264, Issue 1-4, pp.219233

Remeika, P., 1995, Basin tectonics, stratigraphy, and depositional environments of the western Salton Trough detachment:The 1995 San Diego Association of Geologist's Field Trip Guide to Anza-Borrego Desert State Park, California. In P. Remeika and A. Sturz (eds.), Paleontology and Geology of the Western Salton 
Trough Detachment, Anza-Borrego Desert State Park, California. Field Trip Guidebook and Volume for the 1995 San Diego Association of Geologists Field Trip to Anza-Borrego Desert State Park, Vol. 1, p 3-45.

Rial J. A., M. Elkibbi, and M. Yang, 2005, Shear-wave splitting as a tool for the characterization of geothermal fractured reservoirs: lessons learned, Geothermics, Vol. 34, Issue 3, pp.365-385

Ruisaard, C. I., 1979. Stratigraphy of the Miocene Alverson Formation, Imperial County, California. Master of Science Thesis, San Diego State University, 125 p.

Winker, C. D., and Kidwell, S. M., 1996, Stratigraphy of a marine rift basin: Neogene of the western Salton Trough, California. In Abbott, P. L., and Cooper, J. D., (eds.), Field conference guidebook and volume for the annual convention, San Diego, California, May, 1996, Bakersfield, California, Pacific Section, American Association of Petroleum Geologists, p. 295-336.

Xu, Chuandong and Stewart, R, 2004, Using 3D multi-component seismic data, logs and VSP to interpret a sand-shale oil reservoir: EAGE 66th Conference \& Exhibition - Paris, France, 7-10 June 2004 


\section{Appendix C}

\section{Paper 2 Now in Peer Review}




\title{
Advantages of Joint Interpretation of P-P and P-SV Seismic Data in Geothermal Exploration
}

\author{
Shuijian Wei ${ }^{1}$, Michael V. DeAngelo ${ }^{2}$, and Bob A. Hardage ${ }^{2}$ \\ (3) Petroleum Exploration and Production Research Institute, Sinopec \\ (4) Bureau of Economic Geology, The University of Texas at Austin, Austin, \\ TX
}

\begin{abstract}
Conventional P-P seismic images of geothermal reservoirs are often poor quality because P-P data tend to have a low signal-to-noise $(\mathrm{S} / \mathrm{N})$ ratio across geothermal prospects. Fracture identification, fluid prediction, and imaging inside areas influenced by thermally produced steam are some of the challenges facing geothermal explorationists. In this paper, we show that multicomponent seismic technology is effective for addressing all of these challenges across geothermal reservoirs, even when P-P data are low quality. Although multicomponent seismic technology has advantages in geothermal exploration, there are not many published examples of multicomponent seismic data being used to characterize geothermal reservoirs. This paper provides data examples that illustrate advantages of multicomponent seismic technology for imaging within and below zones having low saturations of steam, estimating fracture attributes, analyzing reservoir trapping structures, differentiating lithologies, and predicting spatial distributions of pore fluids. All examples we show are from Wister geothermal field in southern California.
\end{abstract}


Keywords: multicomponent, interpretation, geothermal reservoir, Wister

\section{Introduction}

Conventional P-P seismic technology often does not provide information that geothermal explorationists need to optimize geothermal energy production, usually because P-P data have low signal-to-noise $(\mathrm{S} / \mathrm{N})$ in numerous geothermal environments. The reasons why P-P data have low $\mathrm{S} / \mathrm{N}$ values across geothermal systems vary from prospect to prospect, but common causes are complex faulting, high-attenuation of $\mathrm{P}$-waves in zones having low concentrations of steam in rock pores, anisotropic wavefield propagation velocities, and dramatic lateral variations in P-wave velocities in geothermal strata.

Joint interpretations of P-wave and S-wave data across oil and gas prospects provide more information about subsurface structures, lithology distributions, and pore-fluid saturants than do interpretations of only P-P data [Stewart, 2010]. Fundamentally, S-wave seismic data have equal value to Pwave data in geological interpretations, which leads to the conclusion that seismic stratigraphy analyses in any geologic province should be based on joint interpretations of $\mathrm{P}$ and $\mathrm{S}$ data rather than restricting interpretation to only singlecomponent P-wave data [Hardage, et al., 2011]. Our reason for publishing this work is to provide a case history that emphasizes the importance of joint interpretations of $\mathrm{P}$ and $\mathrm{S}$ data across geothermal areas. Our study utilizes 3-D converted-S (P-SV) data acquired at Wister geothermal field in the southern 
portion of the Imperial Valley of California. These multicomponent data were acquired using vertical vibrator sources and single-point multicomponent (3-C) geophones.

\section{Gas Cloud Imaging}

The ability of multicomponent seismic data to image within gas clouds and beneath shallow gas zones is well documented [Thompson, 2005, Barkved, 2004]. Compared to liquids, any gas, including hot steam, transmits only low amounts of P-wave energy. Thus gas-filled pores attenuate P-waves because a P-P wave mode propagates through both the rock framework and the fluids in the rock pores. S-waves, on the other hand, pass through gas-invaded zones almost undiminished because S-wave displacements propagate through only the rigid framework of a rock.

In our study, a multicomponent 3D survey extended across several blurred P-P seismic zones of Wister field where it appeared invading hot steam attenuated P-P reflection signal. We conducted the interpretation described here using the assumption that P-P data quality at Wister field was degraded when zones of low-saturation of steam existed within the seismic image space.

Because P-wave seismic data consistently had a low signal-to-noise ratio in these steam-invaded intervals, stratigraphy within and beneath these zones could not be properly evaluated with P-P data. In contrast, P-SV data provided valuable images within these steam-affected layers, showed local faults, and allowed underlying structure to be interpreted. 
An example that illustrates the principle that $\mathrm{P}-\mathrm{P}$ reflection events are difficult to observe within a steam-invaded zone, whereas P-SV reflections are reasonably obvious and interpretable, is displayed as Figure 1. In this comparison, P-P reflections inside the elliptical data window fade out, but P-SV reflections remain bold. A second example that demonstrates P-SV data below a steam-affected layer tend to be more interpretable than are P-P data is shown as Figure 2. In this latter example, P-P data enclosed by the rectangle dim out, but P-SV data do not. Examples such as these at Wister field caused us to conclude multicomponent seismic technology is essential for interpreting any geothermal reservoir system where there is a possibility that some strata may have a low saturation of steam in their pore systems. A large attenuation of P-P reflection signal can be caused by a surprisingly small gas (steam) saturation of only a few volume percent.
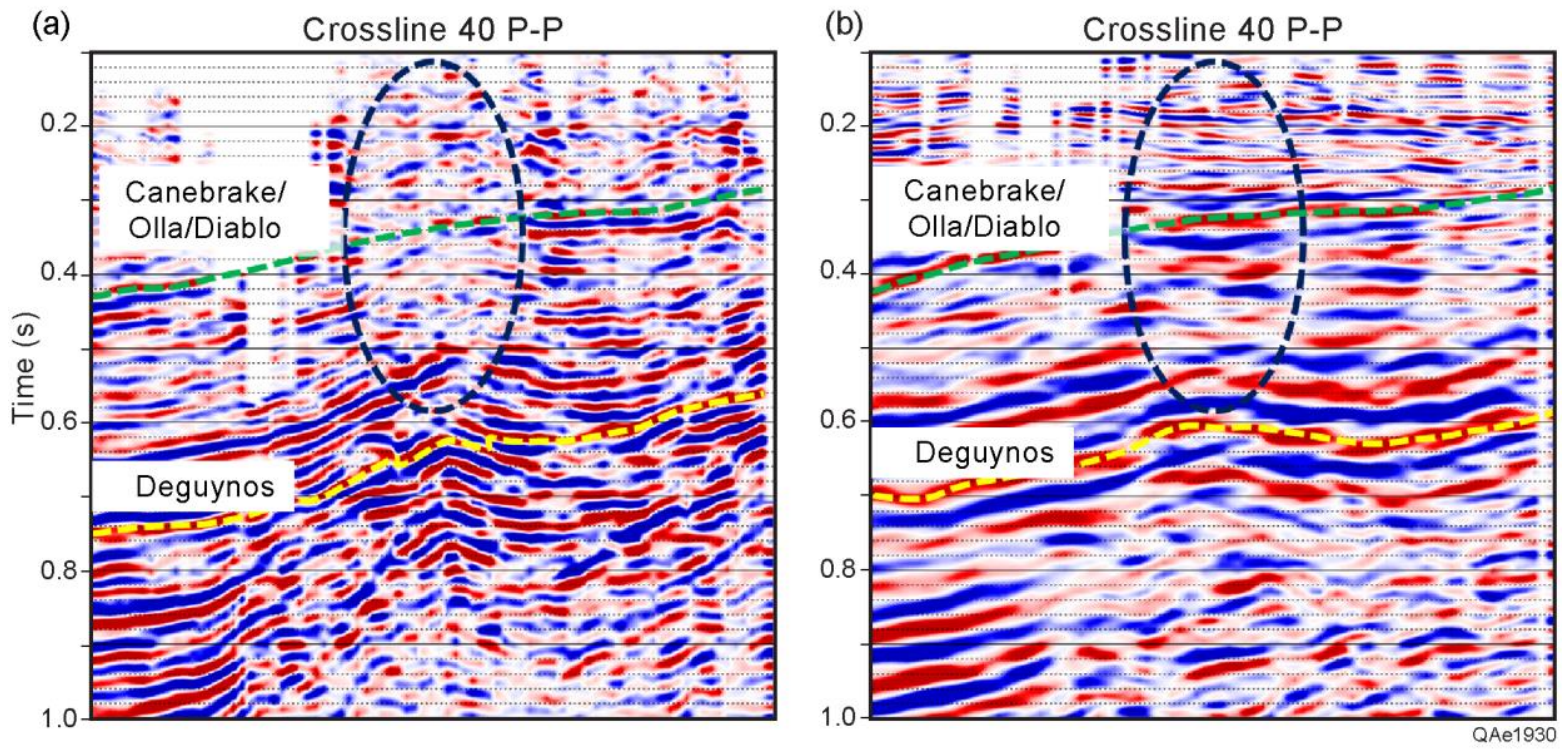

Figure 1. Imaging within gas clouds. (a) P-P profile across an area interpreted to be affected by a shallow, low-saturation of hot steam. P-P reflections are severely attenuated (dashed data window). (b) P-SV image along the same 
profile. P-SV reflections are robust and interpretable.
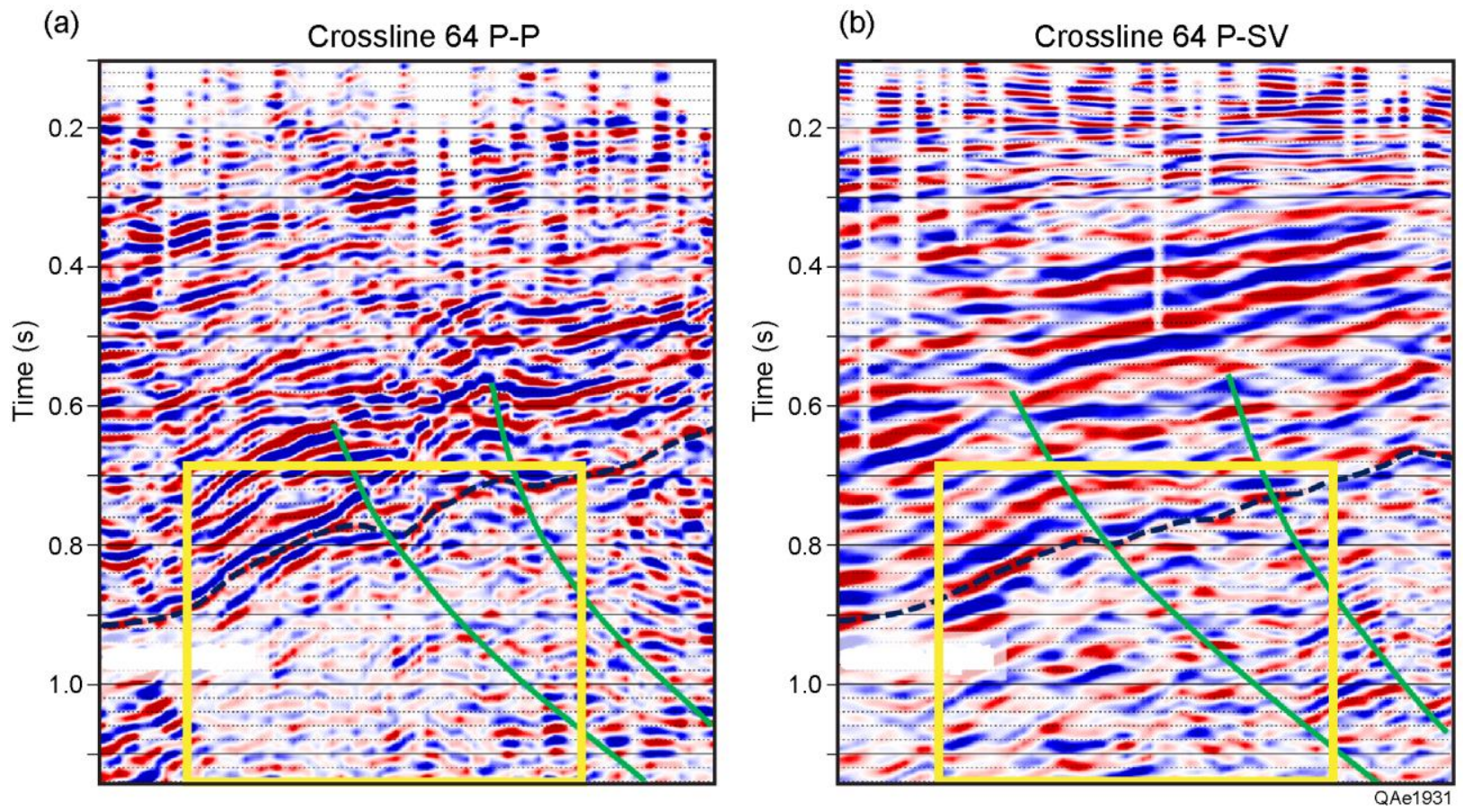

Figure 2. Imaging across an interval interpreted to be invaded by a low saturation of high-temperature steam. (a) P-P data in the interval (blue rectangle) are degraded and difficult to interpret. (b) P-SV profile is not degraded as severely as $\mathrm{P}-\mathrm{P}$ data and contains numerous interpretable events.

\section{Fault and Fracture Identification}

Previous studies have documented the principle that P-SV data provide better resolution of faults than P-P data do (Hardage, et al., 2011; Cary and Couzens, 2000). This same observation is verified by multicomponent seismic data across Wister geothermal field. Numerous examples can be extracted from the Wister P-P and P-SV data volumes to illustrate S-wave data provide more robust images of reservoir faults than do $\mathrm{P}$-wave data. Two section-view comparisons of $\mathrm{P}$ and $\mathrm{S}$ depictions of faults are displayed as Figures 3 and 4 . In 
each figure, data windows are draw to indicate where interpreted faults are

located. Visual inspection of these profiles confirms that in each case, P-SV data show better evidence of reservoir-related faults than do P-P data. Other examples could be illustrated from Wister field.
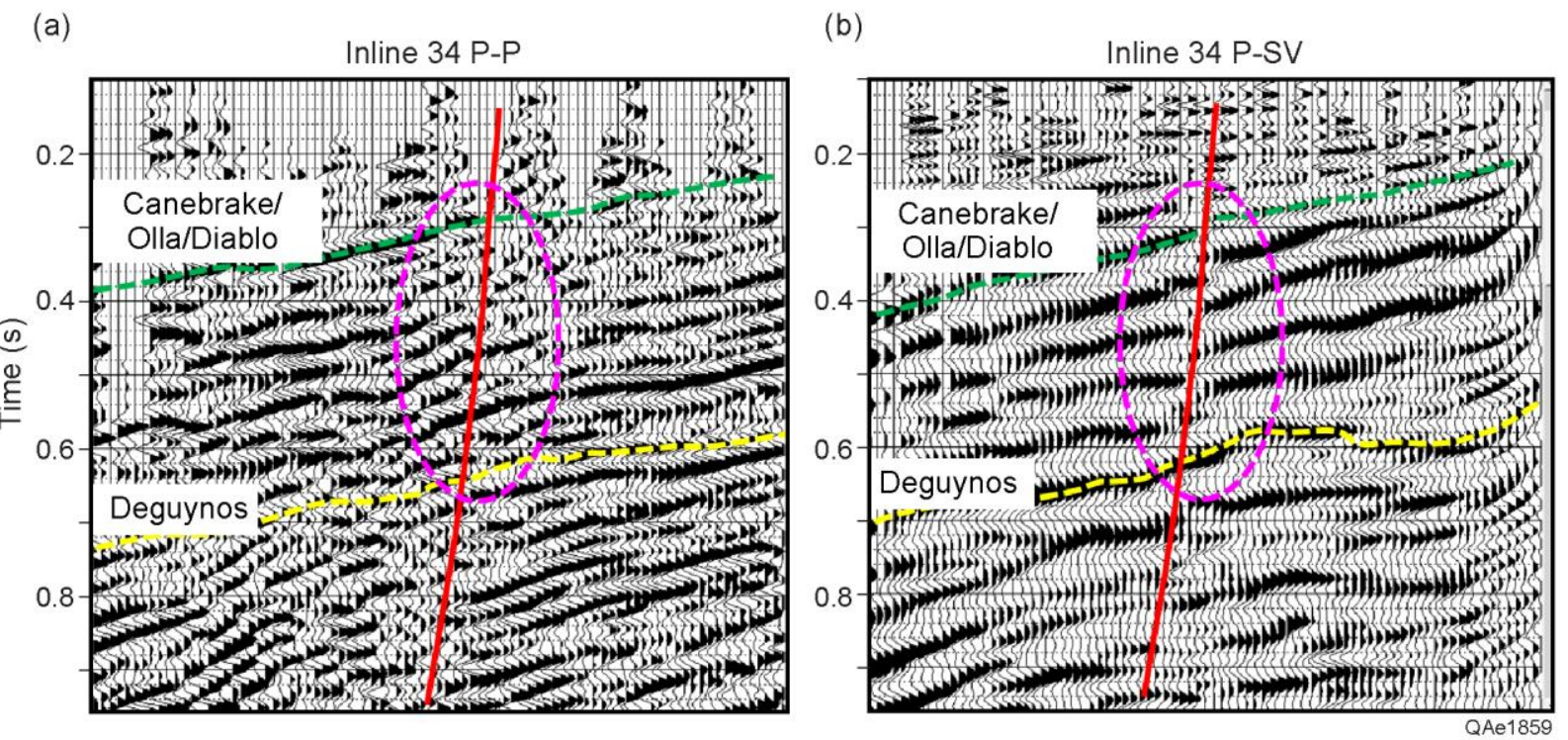

Figure 3. Inline seismic profile. The position of this profile is indicated by line segment labeled A on the coherency map displayed as Figure 5. (a) Interpreted P-P profile. (b) Interpreted P-SV profile. The indicated fault is easier to interpret inside the P-SV data window. 
(a)

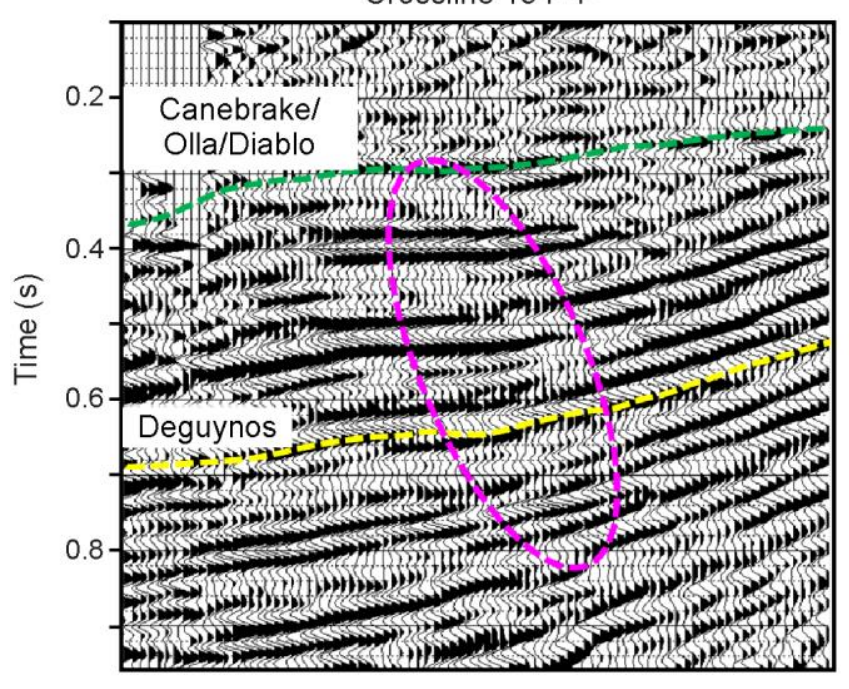

(b)

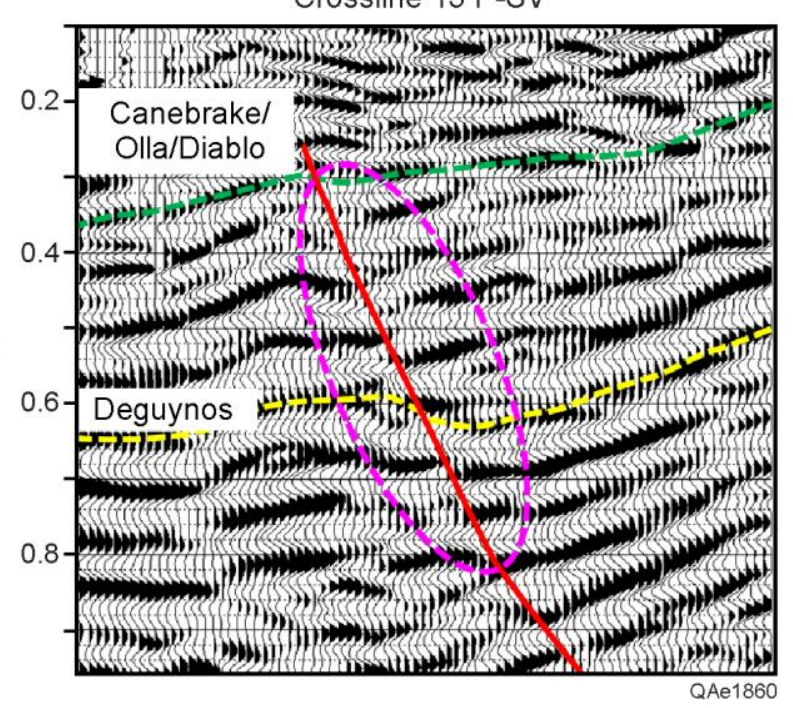

Figure 4. Crossline seismic profile. The position of this profile is indicated by line segment B on the coherency map displayed as Figure 5. (a) Interpreted P-P profile. (b) Interpreted P-SV profile. The indicated fault is easier to interpret inside the P-SV data window.

These examples evaluate the Wister seismic data volumes from a sectionprofile point of view to establish the principle that S-wave data react more strongly to faults than do $\mathrm{P}$ waves. This important fault-interpretation principle can also be illustrated using map views of P-SV and P-P coherency attributes to show that fault systems and fracture trends are better seen when they are viewed using P-SV coherency than when they are depicted with P-P coherency values (Fig. 5). The P-P coherence attribute map (Fig. 5a) has more areas of chaotic discontinuity than does the P-SV attribute map, and it is difficult to identify where faults are located using P-P reflection coherency. In contrast, discontinuities on the P-SV coherence attribute map (Fig. 5b) organize into numerous narrow trends that coincide with interpreted faults observed in section 
view

(Figs. 3 and 4). Spatial distributions of faults and fractured zones can be estimated with greater confidence using the P-SV coherency map (Fig. 5b) than the P-P coherency map (5a). Thus the principle that fault and fracture interpretations are better done by combining $\mathrm{P}$ and $\mathrm{S}$ seismic data than using only P-wave data is supported by both section views and map views of faultsensitive and fracture-sensitive seismic attributes.
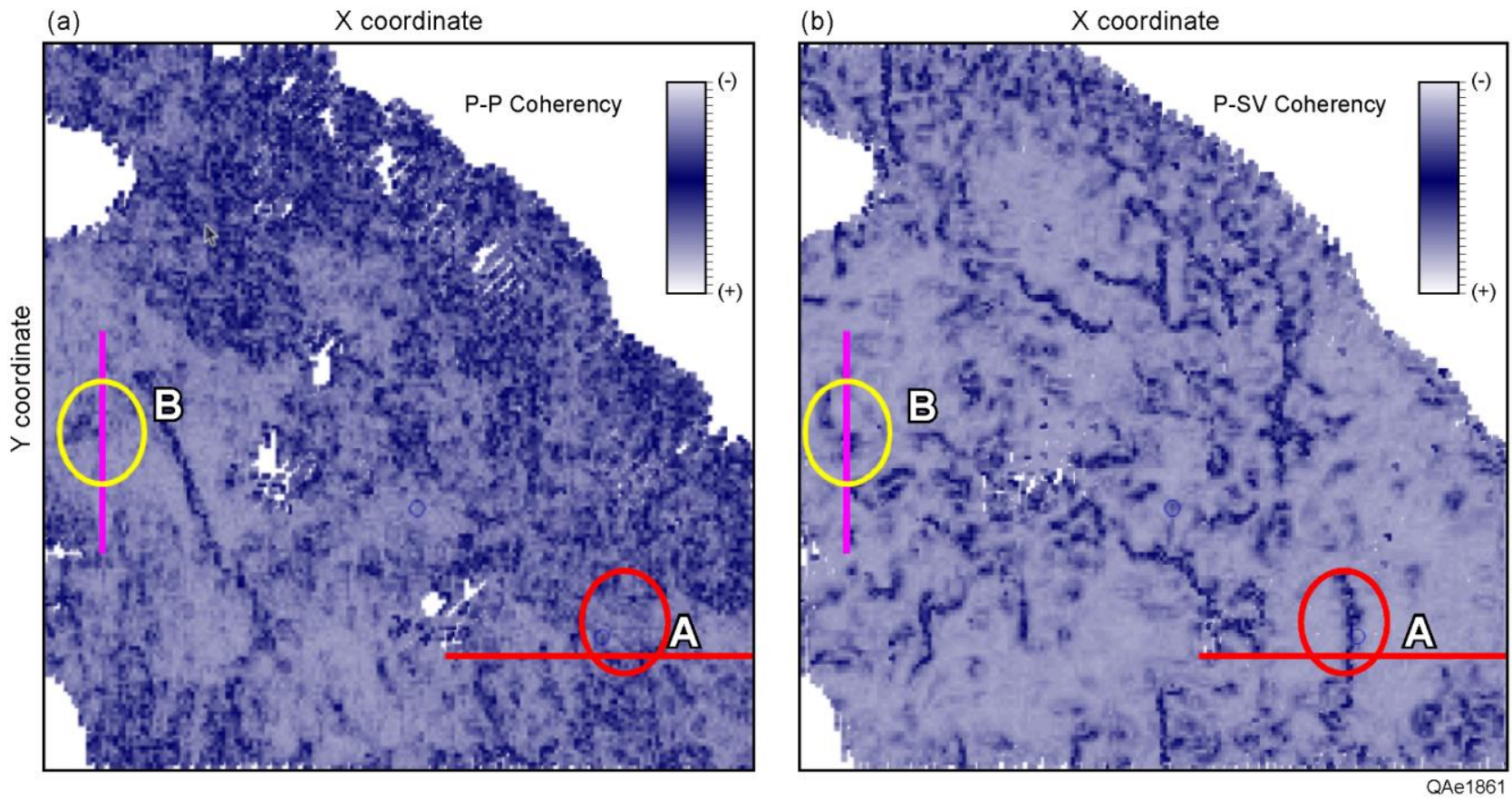

Figure 5: Coherency maps at the bottom of the Canebrake/Olla/Diablo formation, a geothermal reservoir interval at Wister field. Section views of profiles $A$ and $B$ are shown on Figures 3 and 4. (a) Coherency attribute extracted from P-P data. $\mathrm{P}-\mathrm{P}$ coherency tends to be erratic and unorganized. (b) Coherency attribute extracted from P-SV data. In several areas, P-SV coherency organizes into narrow trends that indicate faults within the reservoir interval. 


\section{Seismic Structure Analysis}

The value of multicomponent seismic technology in exploration and development of stratigraphic traps in oil and gas prospects is increasingly recognized. However, the importance of joint interpretation of $\mathrm{P}$ and $\mathrm{S}$ data for improved structural analysis is less emphasized. In this context, we use the term "structure" to mean the geometrical shape of strata that may or may not be related to local faulting, and in some cases may be more related to stratigraphic processes than to tectonic processes. We show two examples as Figures 6 and 7. In the first comparison, P-P data inside the circled area indicate the targeted structure has a relatively constant down-to-the-left dip (Fig. 6a). In contrast, P-SV data imply the structure has an anticline appearance (Fig. 6b) and show the presence of a fault (not labeled) immediately to the right of the structure, close to the circle circumference. This fault is not obvious on the P-P data (Fig. 6a). Whatever the cause, two distinctly different structural pictures are presented by P-P and P-SV data. In some cases, the only way to establish confidence as to which wave mode, P-P or P-SV, provides the more accurate structural geometry will be to drill one or more evaluation wells. 

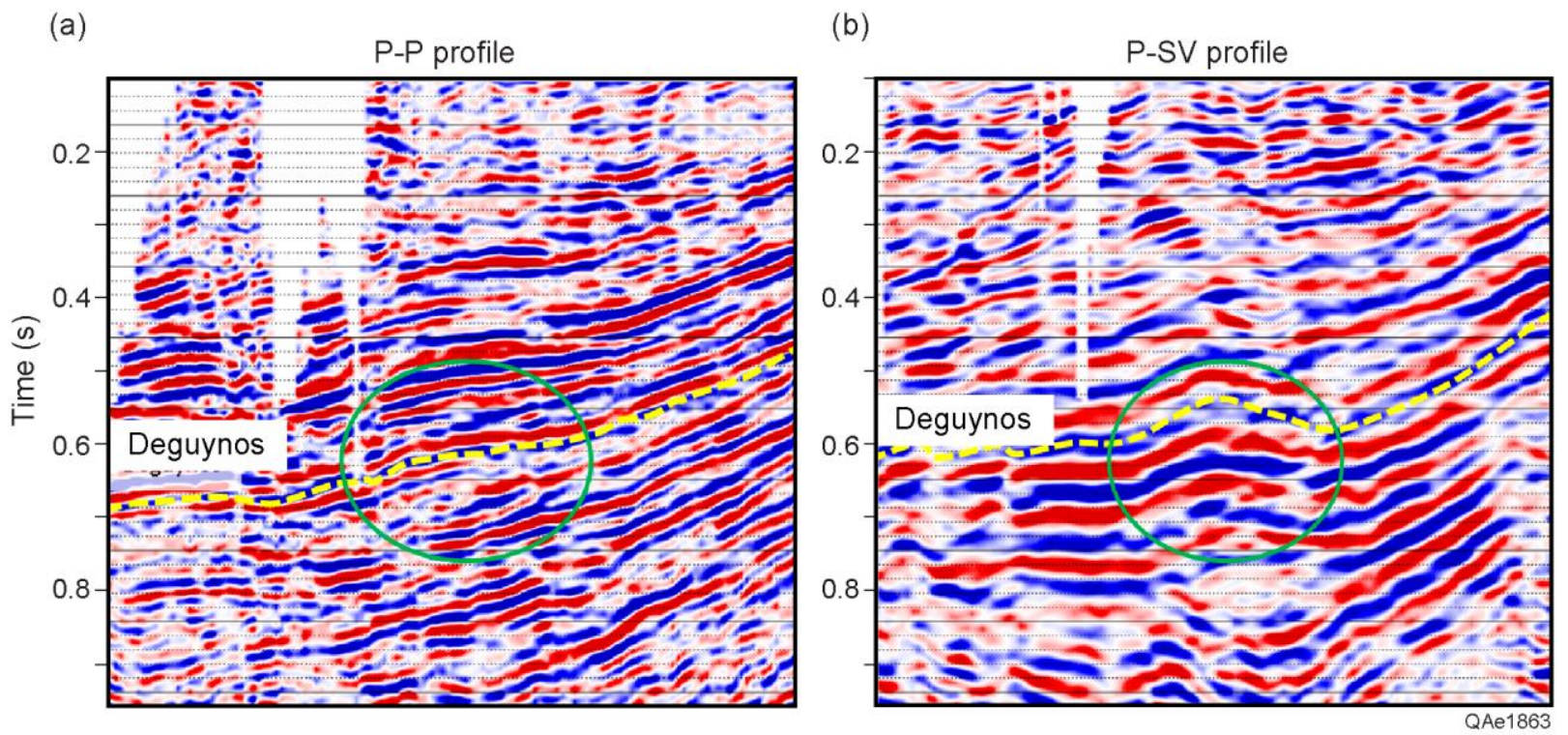

Figure 6: Interpreted seismic profiles. (a) Interpreted P-P profile implies the structural shape is a relatively constant dip. (b) Interpreted P-SV profile shows structure to be an anticline.

The comparison displayed as Figure 7 shows a situation at Wister field where both P-P and P-SV data portray a targeted structure (labeled A) as a narrow anticline. However, the two wave modes present a different picture as to the vertical dimension of the structure, with the vertical anticlinal effect being taller in the P-P image than in the P-SV image. In the P-P data, anticlinal folding continues in data window B. In contrast, P-SV data show no anticlinal folding in interval B. Drilling additional wells will be the most definitive way to determine which wave mode (P-P or P-SV) provides the more reliable structural picture at this location. 
(a)

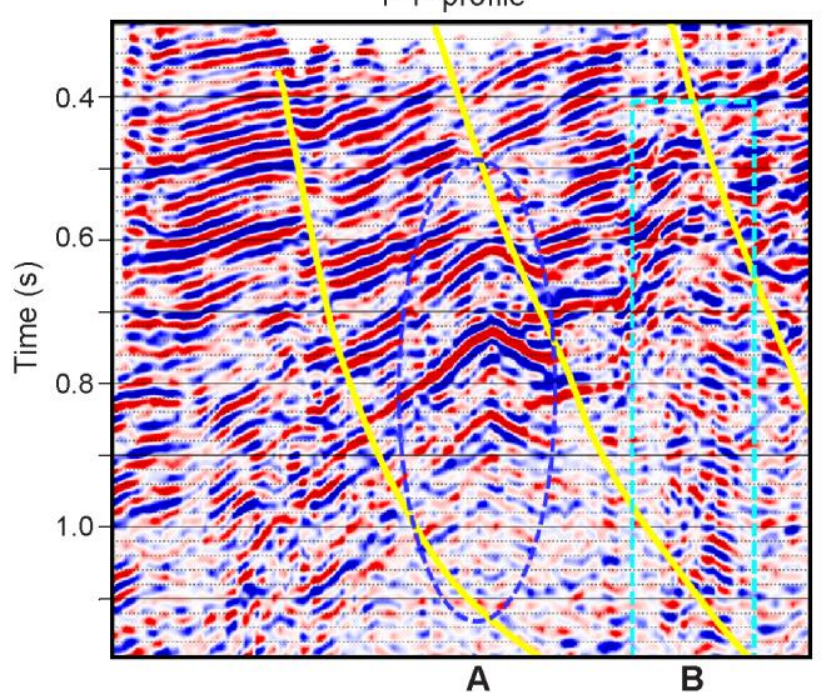

(b)

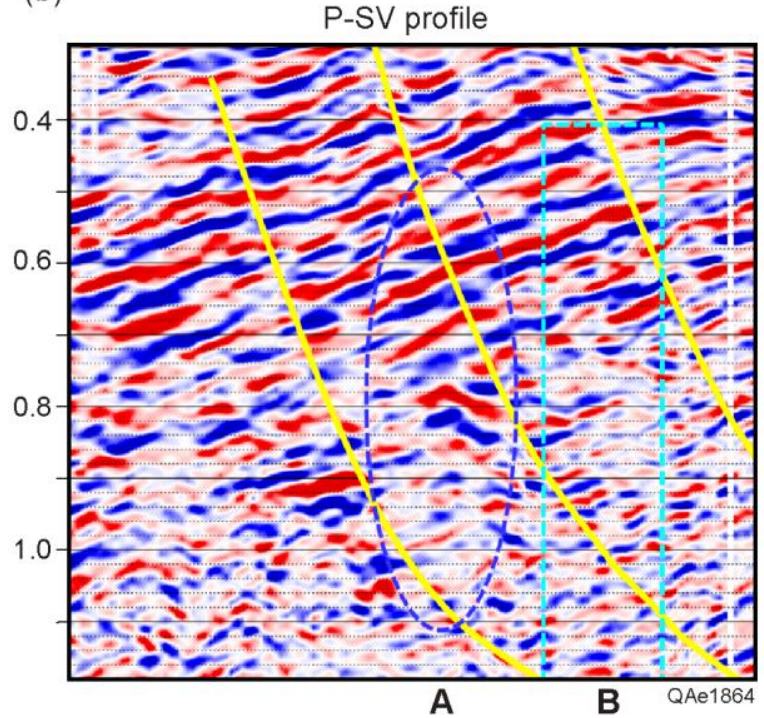

Figure 7: Set 1 of interpreted inline seismic profiles. (a) P-P data show a stacked sequence of fault-related anticlines (windows $A$ and $B$ ) that span an extensive depth interval. (b) P-SV data show one deep anticline in A, but not an extensive vertical sequence of anticlines, and no anticlines in window $B$.
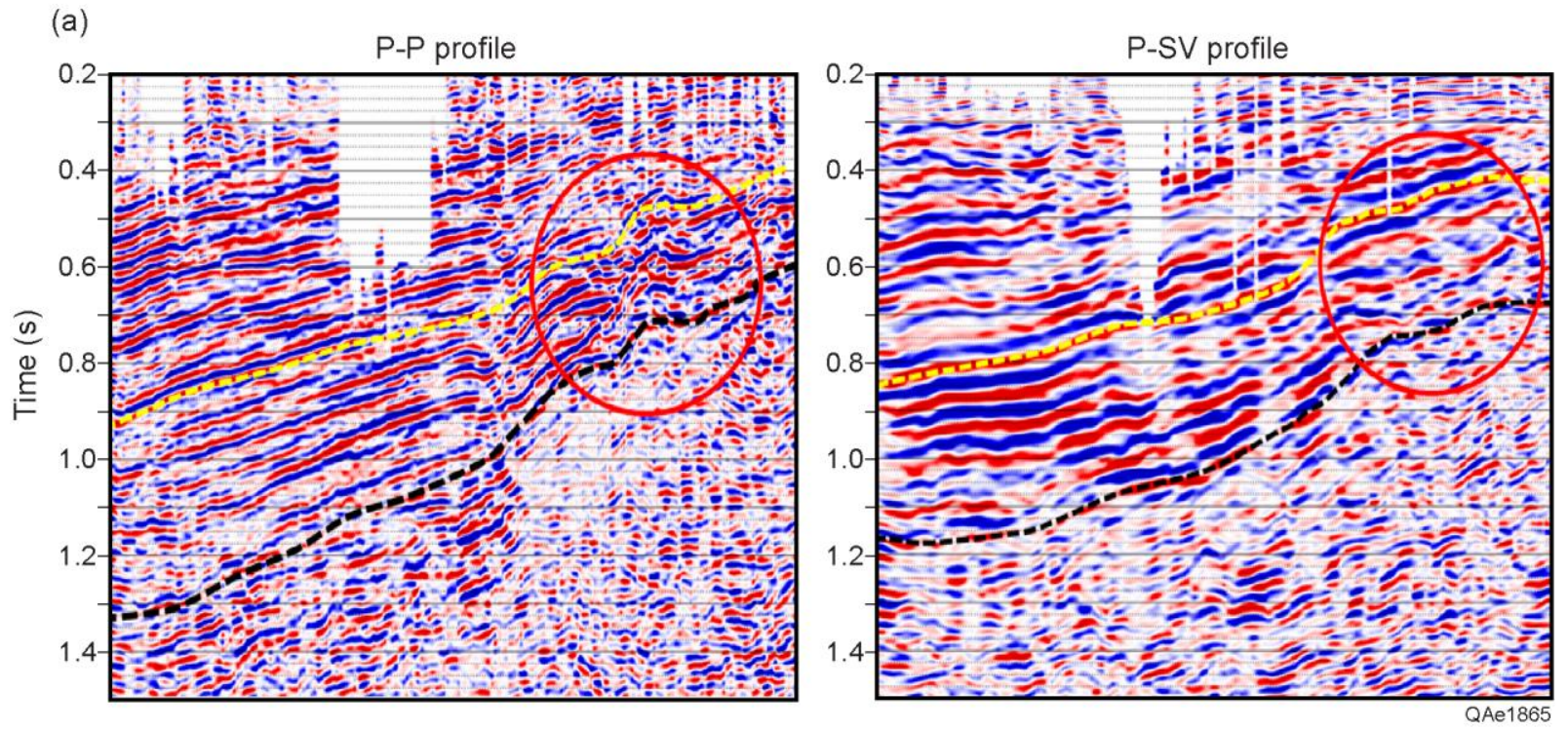

Figure 8. Set 2 of interpreted inline profiles. (a) P-P seismic data show an anticline structure. (b) P-SV seismic data do not show an anticline but indicate the structure has a relatively constant dip in which there are several downlapping terminations of individual units. 
A third scenario is depicted in Figure 8. Here, P-P data infer the presence of a small anticline inside the circled area (Fig. 8a); whereas, P-SV data indicate the structure has approximately constant dip (Fig. 8b). We have no data that will allow us to confirm which structural picture is correct - the P-P picture or the PSV picture. The important point is that we have presented three examples of structural interpretations and found that each wave mode (P-P and P-SV) provides a different possibility for establishing the structural picture across Wister field. As interpreters, our opinion is that such contrary views must be given equal weight unless, and until, there is a firm reason to conclude one wave mode involves faulty data or improper imaging. An important conclusion is that in prospects where there is any possibility that there may be low gas saturations that affect P-P data, serious weight must be given to structural analyses based on P-SV data.

We close this section on structural interpretation by considering a feature that is synclinal in nature, not anticlinal. The seismic profiles to be compared are exhibited on Figure 9. The circled data window on Figure 9a encompasses two levels of stacked syncline-appearing P-P reflections. This syncline appearance is absent on the P-SV image in Figure 9b. This feature is genetically related to local faults A and B. Fault A can be confidently interpreted in map view across a large portion of the P-SV image space and thus is draw as a solid line in Figure 9b. However, fault B is difficult to see in any sizeable area of the P-P data volume, which is why it is shown as a dash line in Figure 9a. The boldness of the synclinal reflections in P-P image space caused us to temporarily consider the 
possibility the feature was a stacked depositional channel controlled by local faults. However, the feature could not be mapped across an area large enough to verify that it had any topographic resemblance to a channel. This example enforces our position that P-P and P-SV structural interpretations must be assigned equal weights of confidence until supporting data are available to confirm which of the differing interpretations is the more reliable.
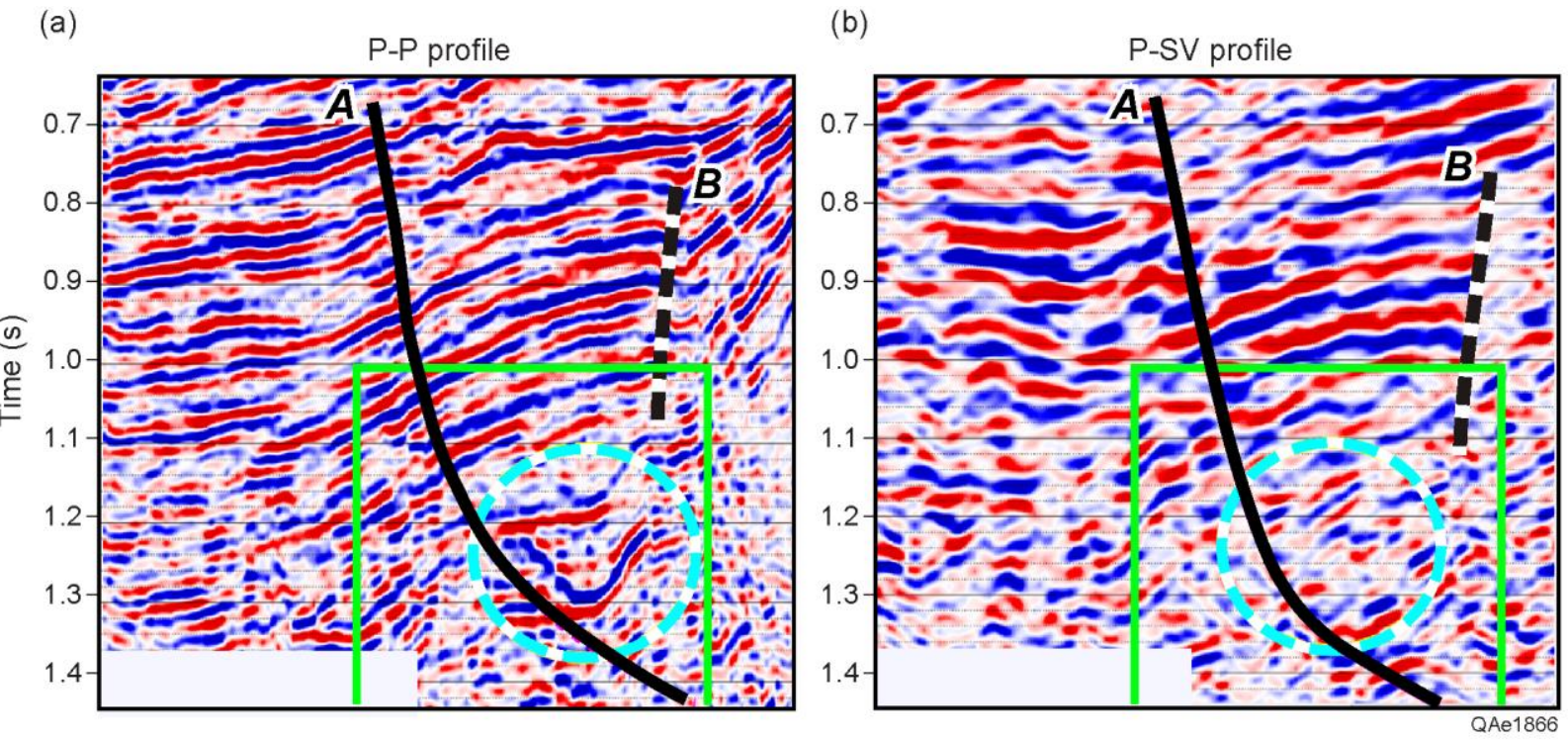

Figure 9: (a) A P-P profile showing a synclinal feature. The feature is suggestive of a channel but could not be mapped over a sufficient area to conclude a channel interpretation is justified. (b) The corresponding P-SV profile provides no evidence of a synclinal feature. 


\section{Fluid Prediction}

The procedure described in this section uses numerical estimates of the effective frequency bandwidths of $P$ and $S$ data to estimate where variations in type and volume of pore fluid occur across a seismic image area. This seismic attribute (effective frequency bandwidth) is only one of numerous interesting, but unproven, parameters that can be created in a joint interpretation of $P$ and $S$ data. We will make several assumptions in order to apply the concept to Wister field and to general application across geothermal prospects.

As $\mathrm{P}$ and $\mathrm{S}$ waves propagate through a layered rock system, the frequency content of each wave mode is affected by several factors: the type of rock encountered on each raypath, the layered structure of the rocks, variations in porosity, type of fluid filling the rock pores, and other rock/fluid properties. For simplicity, we will segregate these effects into factors associated with the rock matrix and factors associated with the type of fluid filling the rock pores. Rock layering will affect $P$ and $S$ data differently if $P$ and $S$ wave modes have significantly different wavelength spectra. We will thus make an additional assumption that to first order, the P-P and P-SV data at Wister field have approximately equal wavelength spectra.

The effective frequency bandwidth of P-P data at the Canebrake/Olla/Diablo reservoir interval at Wister field is displayed as Figure 10a. A generalized low-to-high color bar scale is used to indicate effectivefrequency bandwidth because specific numbers are not important in this interpretation strategy. Spatial variations in this frequency parameter are the 
result of all of the wavefield effects named above, and no doubt additional effects not mentioned. There are so many possible reasons for frequency variations in $\mathrm{P}$ and $S$ data that it is not possible to sort out which frequency effect on the displayed map might be caused by spatial variations in type of pore fluid or in volume of pore fluid. One possibility for isolating frequency variations caused by spatial changes in type and quantity of pore fluid is to calculate the ratio of P-P and P-SV effective frequency bandwidths. This ratio for the Canebrake/Olla/Diablo geothermal reservoir interval is displayed as Figure 10b. The color bar associated with this map is assigned numerical values in contrast to the color bar in Figure 10a.

To first order, when the previous assumptions are applied, P-P and P-SV data tend to be equally affected by factors related to the matrix of the rock encountered on their respective travel paths. In contrast, pore-fluid effects are more pronounced in P-P data than in P-SV data. Thus matrix-related effects on effective frequency P-P and P-SV bandwidths approximately divide out of the ratio parameter displayed in Figure $10 \mathrm{~b}$ and cause the spectral ratio to be dominated by effects caused by spatial variations in pore fluid. Because higherfrequency components of P-P data tend to be attenuated when P-P waves travel through an increasing amount of pore-trapped gas, a tentative interpretation of the data displayed on Figure $10 \mathrm{~b}$ is that lower values of the ratio of effective frequency bandwidth indicate where there are the largest pore volumes of hot stream, which can be caused by increasing concentration of steam, increased reservoir porosity, or both. The value of effective frequency bandwidth ratios for 
estimating spatial distributions in pore fluids is yet to be determined. We include the discussion of this parameter here only as an example of the numerous rocksensitive and fluid-sensitive seismic attributes that can be calculated and utilized when geothermal interpreters perform joint interpretations of $\mathrm{P}$ and $\mathrm{S}$ data.
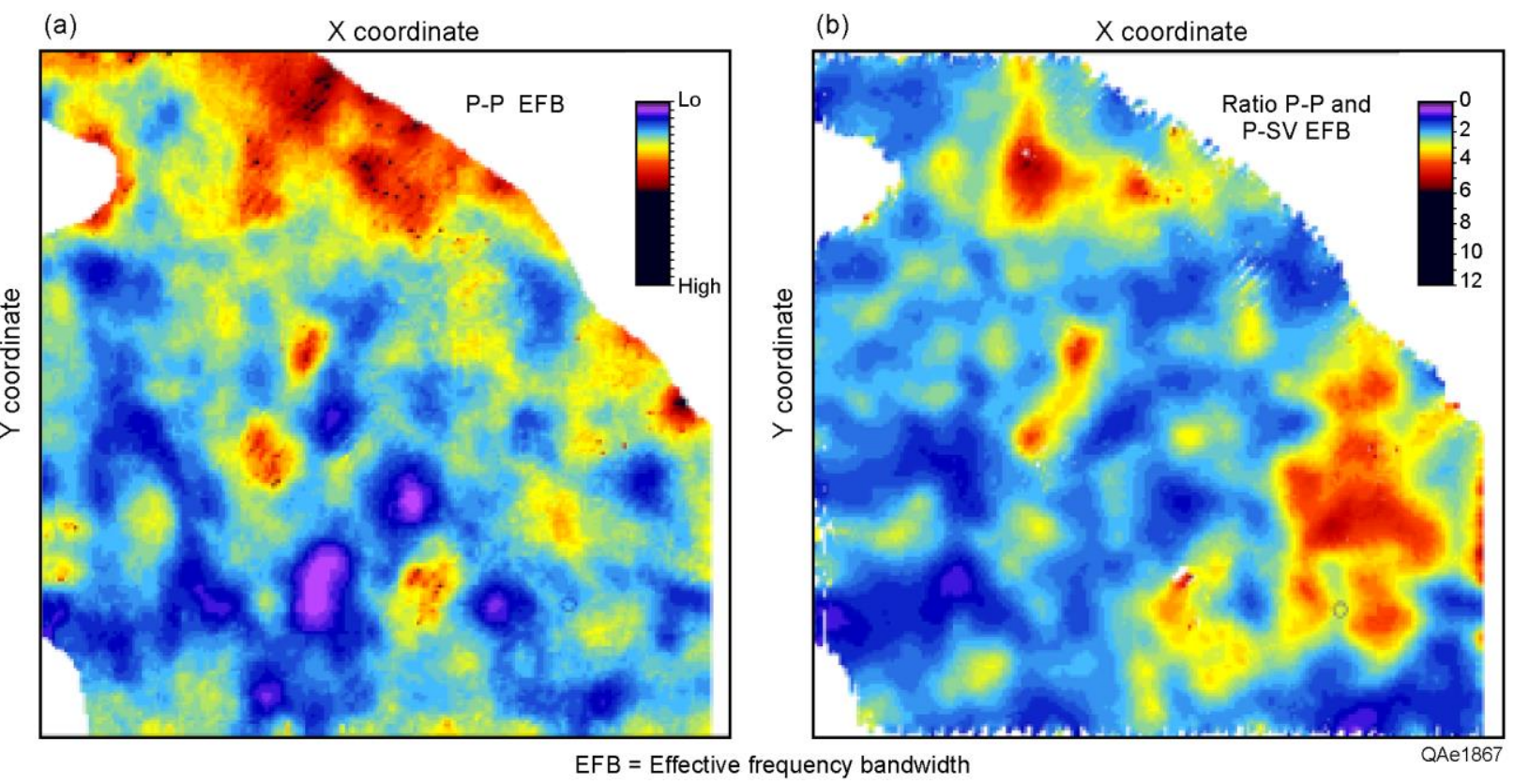

Figure 10. (a) P-P effective bandwidth attribute map across the Canebrake/Olla/Diablo reservoir interval. (b) The ratio of P-P effective bandwidth to P-SV effective bandwidth for the same Canebrake/Olla/Diablo reservoir interval.

\section{Conclusions}

Joint interpretation of $\mathrm{P}$ and $\mathrm{S}$ data provides more information about rock and fluid properties than does an interpretation of only one seismic wave mode, whether that single mode is a P-wave or an S-wave. Our objective in this paper is to encourage the geothermal community to utilize multicomponent seismic data to evaluate geothermal prospects. A common point of view seems to be that because P-P seismic data are so often of poor quality across geothermal 
prospects, it is not economically advisable to invest additional capital to expand the amount and type of seismic data that will be used to characterize and manage geothermal reservoirs. We hope that by our use of $\mathrm{P}$ and $\mathrm{S}$ data across a geothermal field where P-P data are of marginal quality, and then showing the valuable information that becomes available when limited-quality $P$ and $S$ data are used in a joint interpretation at such sites, that geothermal operators will be encouraged to acquire and use multicomponent seismic data in future evaluations of geothermal systems, even if past experiences with P-P data have been disappointing.

We considered the following conclusions to be the key take-away points from the interpretation examples we present in this paper:

1. S-mode data (in our case P-SV data) are more sensitive to faults and fracture zones than are P-mode data. We show compelling examples of this principle in both interpreted section views and in map views of appropriate seismic attributes. Because most geothermal prospects are found in fault provinces, and productive wells in most geothermal reservoirs are related to fracture zones, it seems imperative that the use of S-wave data be expanded within the geothermal production community.

2. If there is any possibility that hot steam in any concentration will invade rock pores at a geothermal field, then $\mathrm{P}$-wave data will attenuate and dim out within and below zones containing this steam, but S-wave data will not. The improvement in image quality and image reliability provided by 
S-wave data can be dramatic. Low levels of steam migration within geothermal systems seem to be a common fluid-movement process.

3. $\mathrm{P}$ and $\mathrm{S}$ data may provide two different views of the structural configuration of strata within a geothermal field. There is no reason to bias a structural interpretation toward the option provided by one wave mode (either $\mathrm{P}$ or $\mathrm{S}$ ) versus the option provided by the companion wave mode (whether P or S). Both structural possibilities should be given equal weight until drilling provides calibration data that justify such bias.

Because P-P data have been successfully used to characterize reservoir systems many years longer than have S-mode data, there is a tendency by all seismic interpreters, whether they concentrate on oil/gas applications or on geothermal applications, to automatically accept a structural picture provided by P-P data in preference to a contradictory picture provided by $\mathrm{S}$ data. This unequal bias toward $\mathrm{P}$-wave structural interpretations is beginning to be questioned by some interpreters.

4. We particularly recommend the use of the $\mathrm{Vp} / \mathrm{Vs}$ velocity ratio for estimating the distributions of rock types within a geothermal system. We did not include an example of the value of the $\mathrm{Vp} / \mathrm{Vs}$ velocity ratio in this paper, but an example is included in our companion paper that appears in this same publication (Wei, et al., 2014). The use of this velocity ratio parameter requires that a dipole sonic log be acquired in one or more local wells to determine how the $\mathrm{Vp} / \mathrm{Vs}$ velocity ratio varies for the 
particular rock types found in any geothermal field that is being interpreted.

\section{Acknowledgements}

This study was funded by the U.S. Department of Energy through contract DE- FE-0005512. The authors thank Ormat for providing digital copies of data across Wister geothermal field. Seismic interpretations were done using software provided by Landmark. The lead author thanks Rui Zhang and Dallas Dunlap for their technical support.

\section{Reference}

Barkved, O., 2004, The many facets of multicomponent seismic data. Oilfield Review, p. $42-56$

Cary, P. W., and R. A. Couzens, 2000, Processing 4-C data from Mahogany field, Gulf of Mexico :Presented at the SEG/EAGE Summer Research Workshop, Boise, Idaho.

Hardage, B. A., M. V. Deangelo, P. E. Murray, and D. Sava, 2011, Multicomponent Seismic Technology, SEG

Stewart, R.R., 2010, Multicomponent seismic exploration: A more complete conversation. Advances in Seismic, Vol. 231, No. 6.

Thompson, C., 2005, Multi-C Survey Cost May be Value. AAPG Explorer. 
Wei, S., M. DeAngelo, and B. Hardage. 2014, Interpretation of multicomponent seismic data across Wister geothermal field, Imperial Field, California:

Interpretation, v. 2 no.2, p xxx-xxx. 